\title{
THE ROLE OF GRAVITY IN FORMATION OF DEEP STRUCTURE OF SHEAR ZONES
}

\author{
Yu. L. Rebetsky, A. V. Mikhailova \\ Schmidt Institute of Physics of the Earth RAS, 123995, Moscow, Bol'shaya Gruzinskaya street, 10, Russia
}

\begin{abstract}
Deformation structures which occur in rock masses in horizontal shear zones are studied with application of theoretical tectonophysical methods of analysis, including mathematical simulation of stresses. The paper presents results of such studies for cases with the rheology of geomedium represented by an elasto-cataclastic body. Taking into account that above the yield stress (in this case, not true plastic dislocation, but cataclastic, i.e. fracturing), results of deformation and the morphology of fractures are dependent on loading modes, in the present study it is proposed to consider the gravity stress state (hereafter GSS) as the initial state of stresses, maintaining deviatory components. Equations based on criteria of the theory of plasticity are presented; they provide for calculation of depths of GSS transition from pure elastic deformation to elastocataclastic deformation. It is shown that for hard and consolidated rocks of the upper crust outside fault zones, the creeping mechanism is associated with cataclastic flow, rather than with dislocations in crystals and grains; this predetermines the dependence of deviatory stresses on isotropic pressure and maintenance of such stresses at a specific level in the rock mass. For the object under study, fracturing occurs at the initial phase of loading under the impact of GSS. Fractures continue to develop during horizontal displacement which is quazi-homogeneous through depth and laterally. The formation of the structural ensemble of fractures is finalized after completion of a long-term phase of displacement of blocks of the crystalline base, i.e. after the phase of localized displacement. By theoretical analyses of the evolution of the state of stresses and the morphology of deformation structures, it is revealed that numerous fractures with shear component are present deep in the middle part of the rock mass; such fractures occur both at the initial, gravity loading phase and during phases of uniform and localized horizontal displacement. Fractures with shear components are mainly formed in the upper part and close to the axial, deep part of the profile. The analysis presented in this publication is necessary for correct reconstruction of loading mechanisms of geological objects. It can also be applicable in exploration geology for forecasting of high fracturing areas of specific morphology.
\end{abstract}

Key words: gravity stress state, deviator stresses, cataclastic flow, initial stresses, evolution of the stress-and-strain state, horizontal shear, fractures, Riedel shears, yield stress.

Recommended by S.I. Sherman 24 February 2011

Citation: Rebetsky Yu.L., Mikhailova A. V. The role of gravity in formation of deep structure of shear zones // Geodynamics \& Tectonophysics. 2011. V. 2. № 1. P. 45-67.

\section{РОЛЬ СИЛ ГРАВИТАЦИИ В ФОРМИРОВАНИИ ГЛУБИННОЙ СТРУКТУРЫ СДВИГОВЫХ ЗОН}

\author{
Ю. Л. Ребецкий, А. В. Михайлова
}

Институт физики Земли им. О.Ю. Шмидта РАН, 123995, ГСП-5, Москва, ул. Большая Грузинская, 10, Россия

Аннотация: В работе на основе результатов теоретического тектонофизического анализа, включающего математическое моделирование напряжений, исследуются структуры разрушения, возникающие в массивах горных пород в зоне горизонтального сдвигания. Реология геосреды - упруго-катакластическое тело. Поскольку за пределом текучести (в данном случае не истинной пластической - дислокационной, а катакластической - трещинной) результат деформирования и морфология разрывных структур зависят от пути нагружения, в работе предлагается в качестве начального рассматривать гравитационное напряженное состояние, сохраняющее девиаторную компоненту. Приве- 
дены выражения, позволяющие на основе критериев теории пластичности рассчитывать глубину перехода гравитационного напряженного состояния от чисто упругого деформирования к упруго-катакластическому. Показано, что для скальных и консолидированных пород верхней коры вне зон разломов механизм ползучести связан с катакластическим течением, а не с дислокациями в кристаллах и зернах, что предопределяет зависимость девиаторных напряжений от всестороннего давления и сохранение определенного их уровня в породном массиве. Для исследуемого объекта разрывные нарушения возникают на начальной стадии нагружения под действием гравитационного напряженного состояния. Их развитие продолжается в ходе квазиоднородного по глубине и латерали горизонтального сдвигания. Окончательное формирование структурного ансамбля трещин происходит после длительного этапа смещения блоков кристаллического фундамента - стадии локализованного сдвигания. Теоретический анализ эволюции напряженного состояния и морфологии структур разрушения показал наличие большого числа трещин со сбросовой компонентой смещения в срединной по глубине части массива, формирующихся не только на начальной - гравитационной - стадии нагружения, но и на стадиях однородного и локализованного горизонтального сдвигания. Разрывы со сдвиговой компонентой смещения формируются преимущественно в верхней и близ осевой, глубинной части разреза. Выполненный анализ не только необходим для корректного восстановления механизмов нагружения геологических объектов, но и может быть использован в разведочной геологии для прогноза областей повышенной трещиноватости определенной морфологии.

Ключевые слова: гравитационное напряженное состояние, девиаторные напряжения, катакластическое течение, начальные напряжения, эволюция напряженно-деформированного состояния, горизонтальный сдвиг, трещины, сколы Риделя, предел текучести.

\section{1. ВВЕДЕНИЕ}

Структуры разрушения в зонах горизонтального сдвигания ${ }^{1}$ всегда являлись объектом пристального внимания геологов, тектонофизиков и сейсмологов. Зоны сдвигания широко представлены в тектонике [Гзовский, 1975; Keller et al., 1982; Harris, Cobbold, 1985; Hancock, 1985; Шерман и др., 1991; Семинский, 2003; и др.]. Можно сказать, с этого геологического объекта закладывались основы тектонофизического моделирования. Начиная с 20-х годов прошлого века выполнено множество лабораторных экспериментов на моделях из влажных глин, песка, парафина. В экспериментах Г. Клоос, В. Ридель, Э. Клоос, Д. Миид, Дж. Чаленко, М.В. Гзовский, С. Стоянов, В.Д. Парфенов, А.Н. Бокун, С.А. Борняков, А.В. Михайлова, К.Ж. Семинский и др. изучали структуры разрушения и деформирования, возникающие в моделях. По наблюдениям за поверхностью моделей выявлено кулисообразное расположение трещин сдвига ( $R$ - и $R$ 'сдвиги) внутри формирующейся зоны горизонтального сдвигания и возникновение трещин отрыва и эшелонов складок в соответствии с ориентацией осей сжатия и растяжения. Установлена зависимость ориентации этих структур от того, в какой обстановке (дополнительное сжатие или растяжение) осуществляется сдвигание. Обобщения результатов моделирования и наблюдаемых природных структур разрушения, выпол-

\footnotetext{
${ }^{1}$ Зона горизонтального сдвигания/сдвига - область, испытывающая относительные горизонтальные смещения, квазиравномерно распределенные на начальной стадии и локализованные в осевой части на продвинутой стадии нагружения. Источником этих смещений являются соответствующие движения в глубине массива (блоков фундамента для пород осадочного чехла) и на латеральном удалении.
}

ненные в работах [Hancok, 1985; Sylvester, 1988; Шерман и др., 1983; Стоянов, 1977; и мн. др.] (рис. 1), стали каноническими, определяющими для геологов и геофизиков возможность интерпретации природных геологических объектов.

В настоящей работе мы опять возвращаемся к проблеме формирования структур разрушения в зонах горизонтального сдвигания в связи с вновь открывшимися обстоятельствами. Прежде всего этот пересмотр связан с потребностями практической геологии, горного дела и сейсмологии. Инициатива этих исследований принадлежит И.Н. Гогоненкову и А.И. Тимурзиеву (Центральная геофизическая экспедиция), обратившим внимание на ряд важных закономерностей, устанавливаемых по результатам 3D-сейсмики. Появились новые геофизические и сейсмологические данные [Гогоненков и др., 2007; Angelier, 2008] о морфологии структур разрушения в глубине зон горизонтального сдвигания, которые не могут быть объяснены в рамках существующих тектонофизических представлений. Эти данные указывают на сложную, изменяющуюся с глубиной морфологию (наклон и простирание, а также, возможно, кинематика) хрупких разрывов, в которой, с одной стороны, проявляется кулисообразность их расположения, подобная $R$-сдвигам в экспериментах, а с другой, для них наблюдается не свойственная экспериментам сбросовая компонента смещения бортов разрывов [Ребецкий и др., 2008, 2009].

В последнее время в работах [Ребецкий, 2008а, 2008б, 2009; Rebetsky, 2008] был детально рассмотрен механизм формирования гравитационного напряженного состояния (ГНС), обусловленного действием массовых сил, которое при боковом стеснении породного материала неизбежно сопровождается накоплением неупругих деформаций и уплотнением - гравитацион- 
$a$

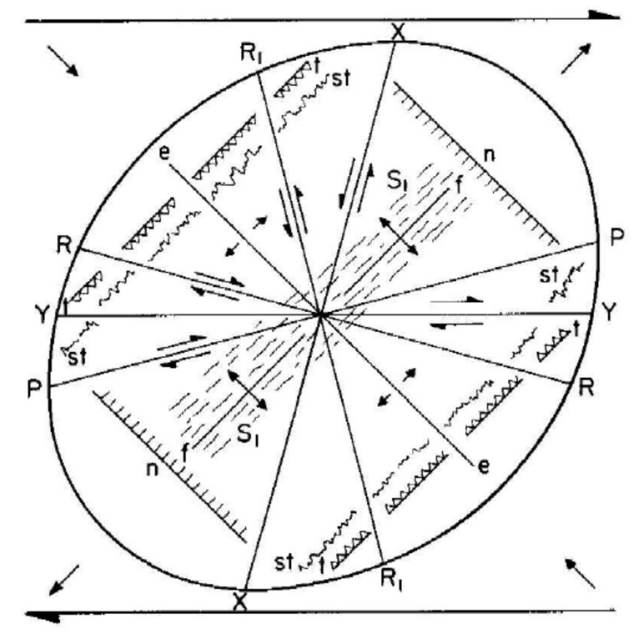

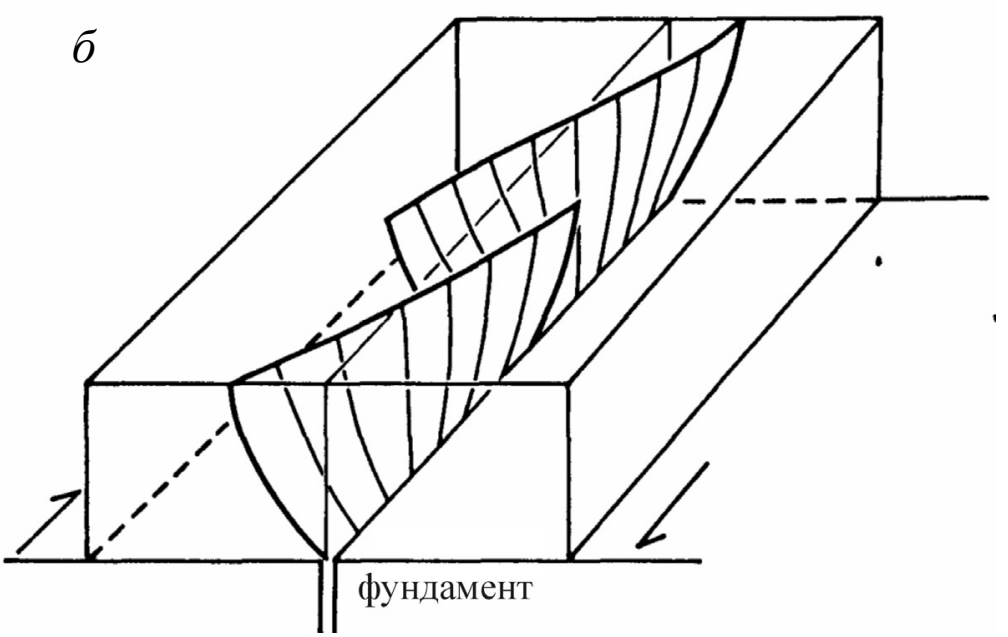

Рис. 1. Прогноз вторичных структур по П. Ханкоку [Hancok, 1985] (a) и формы поверхности $R$-сколов в глубине модели, данный в работе [Sylvester, 1988] (б). $R$ и $R_{1}$ - сопряженные сколы Риделя; $Y$ - магистральные сдвиги; $X$, $P$ - вторичные сдвиги; $e$ - отрывы; $n-$ сбросы; $t$ - взбросы; $f$ - складки; $S_{1}$ - кливаж.

Fig. 1. Forecasted secondary structures according to P. Hancock [1985] (a) and forms of surfaces of $R$-shears inside the model according to [Sylvester, 1988] (б). $R$ и $R_{1}$ - conjugated Riedel shears; $Y$ - major shears; $X, P$ - secondary shears; $e$ - extension; $n$ - normal fault; $t$-thrust fault; $f$ - fold; $S_{1}$ - cleavage.

ное упруго-пластическое уплотнение. Показана роль ГНС в формировании остаточных напряжений в земной коре в условиях вертикальных движений, сопровождающихся эрозией рельефа. На базе этих явлений дано возможное объяснение большим горизонтальным сжимающим напряжениям (большим, чем вертикальные) [Hast, 1969; Марков, 1977] в горно-складчатых областях и областях поднятий платформ. Заметим, что о таком генезисе остаточных напряжений в верхних горизонтах земной коры говорилось ранее в монографии [Гудман, 1987] применительно к проблемам эксплуатации горных выработок. В то же время в более ранних исследованиях, опиравшихся на результаты физического [Гзовский, 1960, 1975; Михайлова, 1989, 2002; Борняков 1981, 1988; Bokun, 2009] и математического [Осокина, 1960, 1963; Rebetsky, 1988] моделирования, влияние ГНС на общее напряженное состояние сводилось в лучшем случае к учету его вклада в изотропное давление. При физическом моделировании это являлось следствием выбора модельного материала в виде влажных глин или песка, а при математическом моделировании достигалось использованием моделей вязкого тела при прямом задании ГНС в виде давления, изменяющегося с глубиной по закону литостатики.

Необходимость корректного учета роли сил гравитации ранее уже неоднократно обсуждалась в работах [Гуревич, 1959; Рамберг, 1970; Шеменда, 1983; Гутерман, 1987; и др.]. В дополнение к вышесказанному об- ратим внимание на то, что анализ выполнения условий подобия в физическом эксперименте [Ребецкий и др., 2009], проведенный в связи с изучением роли ГНС, показал, что главным источником «нарушения» подобия являются трудности в подборе модельных материалов со значениями коэффициента Пуассона $v$, близкими природному $-0.15-0.35$. На этот факт ранее обращал внимание Г.И. Гуревич [1959]. Заметим, что, как показано в работах [Динник, 1926; Джагер, 1975; Шерман, 1977; Ребецкий, 2008а, 2008б, 2009; Rebetsky, 2008; и др.], именно отличие этого коэффициента для природного массива от значения 0.5 и приводит к формированию девиатора гравитационных напряжений. Таким образом, ГНС может создавать вклад в тензор общих напряжений не только в его изотропной части, но и в девиаторной, а это может кардинальным образом менять морфологию структур разрушения. Помимо этого очевидного следствия необходимо также иметь в виду, что при существовании двух равноправных по значимости (по величинам напряжений) факторов воздействия на деформируемый объект роль выполнения условий подобия становится критически важной. В связи с отмеченными выше обстоятельствами в настоящей работе не только выполнен дополнительный анализ условий подобия при физическом моделировании, но и обсуждаются вопросы начального напряженного состояния при моделировании, а также реологии горных пород (проблема релаксации остаточных напряжений). 


\section{2. ПРОБЛЕМЫ ПОДОБИЯ ПРИ ТЕКТОНОФИЗИЧЕСКОМ МОДЕЛИРОВАНИИ}

Основная идея нашего анализа состоит в установлении роли ГНС в формировании структур разрушения в природных объектах и в тектонофизических моделях (физических и математических). Фокусировка внимания на гравитационных напряжениях связана, прежде всего, с тем, что это состояние является первичным, существующим всегда, задолго до начала действия других тектонических сил, формирующих на фоне этого состояния новые геологические структуры. С позиции механики ГНС следует рассматривать как начальное напряженное состояние. Поскольку это состояние в реальных горных породах начиная с некоторых глубин приводит к появлению необратимых деформаций (катакластических, квазипластических, пластических) и изменению девиаторных напряжений в сравнении с чисто упругим состоянием [Давиденков, 1936; Джагер, 1975; Айтматов, 1987; Ребецкий, 2008а, 2008б, 2009; Rebetsky, 2008], необходимо правильно оценить его характерные параметры.

Фактически любое внешнее нагружение горного массива является дополнительным к действию распределенных внутренних массовых сил и создает дополнительные деформации для среды, большая часть которой уже находится за пределом текучести (катакластической в верхних и средних слоях коры [Ребецкий, 2008a, 2008б; Rebetsky, 2008], квазипластической в нижних, истинно пластической ниже границы Мохо [Николаевский, 1979, 1996]). Поскольку процесс деформирования за пределом упругости существенно зависит от пути нагружения [Надаи, 1954], неверная интерпретация начального состояния при математическом моделировании скажется на конечном результате. Естественно, что требование корректного учета начального ГНС относится и к физическому моделированию с тем дополнением, что для него сложнее выполнить условия подобия моделируемого процесса природному из-за ограниченности набора модельных материалов.

Основной вопрос, который требует ответа при рассмотрении роли ГНС: возможно ли объяснить существование за счет его действия больших значений девиаторных напряжений (десятки МПа - сотни бар)?

\section{1. О МОДЕЛЯХ СРЕДЫ И О РОЛИ УПРУГИХ ДЕФОРМАЦИЙ}

Когда выбирается модель среды, то мы во многом предопределяем не только характер распределения напряжений, но и сами величины напряжений в его девиаторной и изотропной составляющих. Так, выбор идеально вязкой (без упругости) реологии, подобной вязкой ньютоновской жидкости, сразу определяет, что начальное ГНС, действовавшее до приложения внешних воздействий к исследуемому объекту, имеет только изотропную составляющую в виде давления $p$, изменяющегося с глубиной по закону литостатики ( $p=p_{l t}=\rho g H-$ литостатическое давление, $\rho g-$ удельный вес пород, $H$ - глубина). Подобные представления о ГНС коры господствовали в геологии до начала прошлого века [Heim, 1878]. По мере развития горных работ и получения данных о поведении пород и о напряжениях [Hast, 1969; Марков, 1977] в горных выработках горняки и геомеханики пришли к выводу, что эти взгляды ошибочны, по крайней мере для верхних горизонтов коры.

Здесь важно отметить, что идеализация реологии без учета упругой составляющей фактически означает, что мы будем рассматривать процесс деформирования для среды, не имеющей деформационной памяти. Если в процессе нагружения не создается значимый рельеф поверхности или границ внутренних слоев различной плотности, то такая среда создает определенный уровень девиаторных напряжений только в тот момент времени, когда действуют внешние силы или задана скорость деформирования. В такой среде не существует понятие остаточных напряжений.

В начале прошлого века в работах по геомеханике [Динник, 1926; и др.] была высказана гипотеза об идеально упругом деформировании пород верхних горизонтов земной коры. В рамках этой гипотезы были выполнены оценки распределения по глубине напряжений, показавшие наличие существенной девиаторной компоненты ГНС, вызванной меньшим в 2-3 раза уровнем напряжений горизонтального сжатия в сравнении с вертикальными напряжениями - литостатическим давлением $\left(\sigma_{z z}=-p_{l t}\right)$. Согласно этой концепции значения максимальных касательных напряжений для горных пород с коэффициентом Пуассона 0.25 составляют $1 / 3$ от литостатического давления ( $\tau=0.333 p_{l t}$ ).

В горном деле использовались данные о напряжениях, следующие из той или иной теории (А. Гейма или А.Н. Динника), в качестве начального состояния при расчетах возмущенного напряженного состояния горного массива, вызванного проходкой подземной выработки. Поскольку наблюдались отклонения в поведении породного массива вблизи горных выработок от того, что давали результаты горно-инженерных расчетов, предпринимались попытки развития теоретических представлений о генезисе напряжений. В частности, в работе Ю.М. Либермана [1962] существование в горном массиве напряжений горизонтального сжатия, повышенных относительно теории А.Н. Динника, но меньших, чем это следовало из теории А. Хейма, связывалось с пластическим деформированием горных пород, возникающим после достижения в массиве на определенных глубинах предельного напряженного состояния (критерии Кулон-Мора или ДруккерПрагера).

Выбор моделей деформационных процессов в верхней коре в виде тела, обладающего упругостью и способностью к формированию необратимых дефор- 
маций (вязких или пластических), отражает наше понимание того факта, что ГНС может отличаться от простого всестороннего литостатического давления, и эти отличия связаны с возможностью сохранения в нем девиаторной составляющей напряжений. Уменьшение уровня девиатора гравитационных напряжений для реальных горных пород вызвано преодолением предела кулоновой прочности, формированием необратимых деформаций и повышением уровня горизонтального сжатия [Джагер, 1975; Ребецкий, 2008а, 20086, 2009; Rebetsky, 2008]. С позиции механики одно это обстоятельство в условиях неоднородного начального напряженного состояния определяет влияние ГНС на поле напряжений, формирующееся в процессе приложения дополнительных внешних воздействий на геологическую среду.

Выше уже было отмечено, что возможность существования девиаторных напряжений ГНС также приводит к усложнению выполнения подобия в физическом эксперименте и тем более к невозможности его автоматического выполнения [Белоусов, Гончаров, 1991; Методы моделирования..., 1988]. Одновременное действие двух факторов (гравитационные напряжения и внешнее нагружение) требует, чтобы в физическом эксперименте они соотносились таким же образом, как и в природе. Это означает, что мы должны в модели выбрать материалы, способные сформировать начальное напряженное состояние от гравитационных сил такое же, как в природе, т.е. необходимо выполнить соответствующие условия подобия по массовым силам. Это также означает, что скорости нагружения в эксперименте должны подбираться в зависимости от геометрии модели и реологии ее материалов.

Все вышесказанное имеет место тогда, когда мы можем твердо говорить о существовании девиаторных напряжений для начального ГНС или когда исследуются процессы, в которых важно влияние всестороннего давления (хрупкое разрушение). Иногда можно услышать утверждение, что за геологические времена девиаторная составляющая гравитационных напряжений релаксирует. В этой связи мы должны ответить на вопрос, может ли произойти полная релаксация девиаторной компоненты гравитационных напряжений как следствие вязкого течения горных пород. Для ответа на него необходимо рассмотреть возможные механизмы релаксации напряжений в горных породах коры.

\section{2. О ВЯЗКОЙ РЕЛАКСАЦИИ ЭНЕРГИИ ФОРМОИЗМЕНЕНИЯ}

Существует несколько механизмов ползучести твердых горных пород [Вернон, 1980], похожей на вязкое течение жидкостей с внутренним трением (здесь имеется в виду возможность диссипации - рассеяния энергии упругих деформаций): диффузионное течение за счет миграции атомов, вакансий и движения дислокаций внутри кристаллической решетки и по поверхности кристалла; дислокационное течение, вы- ражающееся в создании новых внутрикристаллических дислокаций, возникновении трансляционного скольжения, механического двойникования, формирования полос излома и кинкбендов; межзерновая ползучесть (катаклаз) по границам за счет микро- и макроскопических хрупких трещинок, приспособления неудачных контактов зерен или внутризернового деформирования; регенерация и рекристаллизация, сопровождающиеся уменьшением размеров зерен и их большеугловых границ; перемещение с растворением (растворение под давлением, или компрессионная ползучесть), реализующееся в присутствии флюидов; катакластическая ползучесть за счет мегаскопической трещиноватости.

Механизм растворения под давлением требует высокой насыщенности флюида в трещинно-поровом пространстве, что имеет место для зон разломов. Механизмы регенерации и рекристаллизации также приурочены к отдельным участкам разломов с высоким уровнем давления и вне разломов действуют в нижней части коры (регенерация) и в мантии (рекристаллизация требует температур, больших 0.5 от температуры плавления). Поэтому за релаксацию девиаторных напряжений, вызванных массовыми силами, в больших объемах горных пород вне зон разломов отвечают механизмы диффузионной, дислокационной и катакластической ползучести.

Диффузионная ползучесть в верхней и средней коре осуществляется при низких температурах и поэтому имеет самое высокое значение коэффициента вязкости порядка 10 28-32 Па·с [Осокина, 1971; Гзовский, 1975]. Этому коэффициенту вязкости отвечает время релаксации (время уменьшения уровня девиаторных напряжений в $e=2.718$ раза) больше нескольких миллиардов лет. Можно ожидать, что повышенная флюидонасыщенность приводит к ускорению диффузионной ползучести за счет роста дислокаций как следствие химической коррозии (эффект Ребиндера). Это явление в большей степени относится к зонам разломов. Определенное снижение коэффициента диффузионной вязкости для пород осадочных бассейнов, пород средней коры, вероятно, также имеет место. Нам не известны оценки коэффициента диффузионной вязкости как функции флюидонасыщенности пород.

Коэффициент дислокационной вязкости горных пород много меньше диффузионного и для осадочных пород может составлять $10^{16-20}$ Па·с, а для кристаллических и метаморфизированных пород $10^{19-23}$ Па·с. Однако механизм дислокационной ползучести столь эффективно действует только при значениях девиаторных напряжений, близких к пределу текучести (упругости). Заметим, что здесь имеется в виду истинный предел текучести, определяющий начало пластического деформирования кристаллов и зерен. Значение этого предела текучести можно получить только из экспериментов, выполненных в условиях высокого уровня бокового обжатия образцов. Значения предела ис- 
тинной текучести для прочных горных пород составляют 300-500 МПа и более, а для осадочных 50200 МПа (повышенные значения для песчанистых пород, пониженные для глинистых). Наши оценки [Peбецкий, 2009] показывают, что значения 100 МПа девиаторные напряжения для упругого состояния достигают на глубинах 12-13 км. С другой стороны, предел кулоновской прочности осадочных горных пород (предел внутреннего сцепления от первых единиц до $10 \mathrm{MПа)} \mathrm{при} \mathrm{гидростатическом} \mathrm{уровне} \mathrm{флюидного}$ давления достигается уже на глубинах в первые километры. Для прочных горных пород подобное состояние возникает на глубинах 7-8 км, в то время как предел истинной текучести для них достигается вблизи границы Мохоровичича. Это означает, что в коре только вблизи границы $M$ могут возникать условия, благоприятные для механизма дислокационной ползучести.

В трещиноватых горных породах также может возникать катакластическая ползучесть - вязкое течение, обусловленное трещинными деформациями. Это течение не формируется в результате мгновенной реакции на нагружение (катакластическая пластичность), а запаздывает во времени из-за реализации механизма длительной прочности (снижение прочности во времени [Гзовский, 1975]). Коэффициент вязкости для катакластической ползучести сильно зависит от эффективного изотропного давления (тектоническое давление минус давление флюида). Как показано в работах [Ребецкий, 2008a, 20086, 2009; Rebetsky, 2008], релаксация девиатора гравитационных напряжений, происходящая в условиях бокового стеснения, приводит к росту напряжений горизонтального сжатия при неизменности значений вертикальных напряжений, определяемых весом столба горных пород. Это означает, что в процессе релаксации девиаторных напряжений происходит рост всестороннего сжатия и, как следствие, энергия упругих деформаций формоизменения переходит в энергию упругих деформаций всестороннего сжатия [Ребецкий, 2009]. В условиях возрастающего во времени всестороннего давления коэффициент катакластической вязкости растет, приближаясь к значениям коэффициента диффузионной вязкости. Таким образом, катакластическая ползучесть не может привести к полному выравниванию вертикальных и горизонтальных напряжений ГНС из-за повышения сопротивления сухого трения на поверхностях трещин в условиях увеличивающегося в процессе ползучести всестороннего сжатия.

\section{3. ОЦЕНКА ДЕВИАТОРНЫХ НАПРЯЖЕНИЙ ГРАВИТАЦИОННОГО НАПРЯЖЕННОГО СОСТОЯНИЯ}

Выполненный выше анализ показал, что начальное напряженное состояние, существующее в горных породах до приложения внешних тектонических воздействий и обусловленное действием массовых сил -
ГНС, всегда имеет девиаторную составляющую. Ее величина определяется параметрами катакластической пластичности и ползучести, которая развивается в трещиноватых горных породах за счет явления длительной прочности. Для оценки величины девиаторных напряжений требуется высказать определенные предположения о величине флюидного давления в массивах горных пород вне зон разломов, о типе критерия катакластической текучести и знать прочностные и механические параметры конкретных горных пород.

Как было отмечено выше, трещинная текучесть горных пород может проявляться в двух видах. В первом случае она возникает сразу при достижении предельного состояния, определяемого значениями внутреннего сцепления $\tau_{f}$ и трения $k_{f}$ и подобно пластическому деформированию $\left(\tau \leq \tau_{f}+p^{*} k_{f}-\right.$ критерий пластической текучести Кулона - Мора, $p^{*}$ - эффективное давление) [Ребецкий, 2007]. Трещинное течение при длительном действии нагрузки также выглядит подобно ползучести. Ползучее трещинное течение связано с явлением длительной прочности, приводящим к медленному снижению внутреннего сцепления (при развитой ползучести на очень больших временах $\tau_{f}$ может падать вплоть до нуля). Это обстоятельство определяет то, что в процессе катакластической ползучести снижение девиаторной составляющей тензора ГНС более значительное, чем при катакластическом пластическом деформировании. Принимая значения коэффициента внутреннего трения $k_{f}=0.6$, коэффициент Пуассона $v=0.25$ и используя выражение (18) из работ [Ребецкий, 2008a, 2008б; Rebetsky, 2008], можно определить величину дополнительных горизонтальных напряжений, возникающих в процессе ползучести: $\Delta \sigma=-0.286 \cdot p_{l t}$ (гидростатический закон изменения давления флюида с глубиной). На основе этих оценок значение максимальных касательных напряжений составляет около $20 \%$ от литостатического давления $p_{l t}$.

Согласно полученной оценке для глубины 3-4 км (осадочные бассейны) уровень девиатора начальных гравитационных напряжений, с учетом флюидного давления, будет 15-22 МПа. Полученное соотношение девиаторных напряжений и литостатического давления может быть распространено на глубины коры до 5-10 км, где параметры внутренней прочности горных пород наиболее соответствуют наблюдаемым в лабораторных экспериментах [Byerlee, 1978]. Увеличение флюидного давления, приближение его значений к литостатическому способствуют снижению девиаторной компоненты напряжений. Наибольших значений флюидное давление достигает в средней части коры, где имеет место катаклазированное состояние горных пород [Николаевский, 1996] с относительно большим 
объемом трещинно-порового пространства. Вероятно, глубины 10-15 км являются областями, в пределах которых ГНС имеет наибольшее значение максимальных касательных напряжений. Здесь $\tau$ может достигать 40-80 МПа. Для больших глубин коэффициент внутреннего трения может снижаться из-за уменьшающейся размерности трещин, формирующих трещинное течение; здесь породы становятся более плотно упакованными (явление компакции). В нижней коре, где трещинное течение может опускаться на уровень границ зерен, коэффициент внутреннего трения может снижаться до нуля, что должно приводить к исчезновению девиатора гравитационных напряжений $\left(\Delta \sigma \rightarrow 2 p_{l t} / 3\right)$.

Полученные оценки девиаторной компоненты гравитационных напряжений показывают, что эти напряжения достаточно велики и вполне сопоставимы по уровню с напряжениями, обусловленными действием внешних сил [Ребецкий, 2007; Hardebeck, Hauksson, 2001]. Выполненные оценки опираются на стандартное ГНС, формирующееся в условиях осадочных бассейнов, и не учитывают механизм образования повышенных значений напряжений горизонтального сжатия за счет остаточных напряжений [Ребецкий, 2008a, 20086, 2009; Rebetsky, 2008].

\section{4. ВЫБОР ОПРЕДЕЛЯЮЩИХ СООТНОШЕНИЙ ДЛЯ РАСЧЕТА КОЭФФИЦИЕНТОВ ПОДОБИЯ}

Теперь, оценив роль ГНС, перейдем к анализу параметров, определяющих подобие тектонофизического эксперимента природному объекту при исследовании тектоники верхней и средней коры. При математическом моделировании результаты полученных выше оценок напряжений требуют использования модели геологической среды в виде упруго-пластического тела с пределом текучести, зависящим от эффективного давления (тектоническое давление за вычетом давления флюида в трещинно-поровом пространстве), тогда, когда речь идет о процессах, происходящих за относительно короткие интервалы времени, и о процессах хрупкого разрушения. В случаях исследования реакции горного массива на длительно действующие нагрузки и изучения больших необратимых деформаций следует применять модели упруго-ползучего тела. Для моделей, в которых существует начальный рельеф или он формируется из-за приложения внешних нагрузок, коэффициент вязкости модельного материала должен зависеть от всестороннего давления. Если речь идет о моделировании длительных процессов, происходящих в условиях отсутствия латерального градиента начального ГНС (отсутствие выраженного рельефа), возможно использование упруго-вязких и даже чисто вязких моделей среды, так как величины необратимых деформаций, накопленных за длительное время, будут существенно превосходить упругие деформации.

Аналогичным образом следует проводить выбор определяющих коэффициентов подобия и при физическом эксперименте. В частности, применительно к зонам горизонтального сдвигания при постановке задачи исследования структур течения - больших необратимых деформаций - следует ориентироваться на выполнение условий подобия именно для структур вязкого (пластического в обобщенном смысле) течения [Гзовский, 1975]. В этом случае характер взаимосвязи касательных напряжений $\tau$ и скорости деформаций сдвига $\dot{\varepsilon}$ определяется законом вязкого течения. Поскольку для исследуемого механизма рельеф не является определяющим, коэффициент вязкости модельного вещества может не зависеть от всестороннего давления:

$$
\tau=\eta \dot{\varepsilon},
$$

откуда следует соотношение для коэффициентов подобия по напряжениям $C_{\tau}$, вязкости $C_{\eta}$ и времени $C_{t}$ :

$$
C_{\tau}=C_{\eta} / C_{t}
$$

Еще одно соотношение коэффициентов подобия можно получить из уравнения равновесия:

$$
C_{\tau}=C_{g} C_{\rho} C_{L}
$$

Здесь в правой части стоят коэффициенты подобия по ускорению силы тяжести, плотности и линейным размерам.

Подставив в соотношение (2) $C_{\eta}=10^{-14}$ (вязкость влажной глины $-10^{8}$ Па для скорости деформирования $10^{-3}$ сек $^{-1}$ [Михайлова, Осокина, 1973], а пород осадочного чехла $-10^{22}$ Па для скорости деформирования 10 ${ }^{12}$ сек $^{-1}$ ) и $C_{t}=10^{-9}$ (время эксперимента первые сутки, в природе - миллионы лет), находим $C_{\tau} \approx 10^{-5}$. Коэффициент подобия по скорости нагружения согласно

$$
C_{v}=C_{L} / C_{t}
$$

равен $10^{4}$ для коэффициента подобия по геометрии $C_{L}=10^{-5}$ (для мощности модели в первые сантиметры отвечает в природе слой в первые километры). Применительно к модели формирования горизонтального сдвигания скорости относительного смещения бортов природного разрыва на глубине осадочного бассейна в 1 см/год отвечает 3 мкм/сек.

Используя полученное выше значение коэффициента подобия по напряжениям и принимая значения коэффициентов подобия по плотности $C_{\rho} \approx 1$ (влажные глины, песок), из соотношения (3) находим, что коэффициент подобия по ускорению свободного падения $C_{g}$ близок к единице. Указанное значение коэффициента подобия для ускорения свободного падения 
позволяет осуществлять тектонофизическое моделирование в обычных условиях без применения центрифугирования [Рамберг, 1970; Гутерман, 1987; Бокун, 1991; Шерман и др., 1991; Семинский, 2003].

Заметим, что появляющиеся в таком эксперименте структуры хрупкого разрушения - трещинки сдвига и отрыва - следует воспринимать как индикаторы областей повышенной скорости деформирования - повышенного уровня девиаторных напряжений.

Для анализа данных природных наблюдений [Гогоненков и др., 2006; Angelier, 2008] и изучения при моделировании структур разрушения, формирующихся в глубине такой модели, следует использовать материалы, коэффициент подобия которых определяется, прежде всего, из условия подобия начальному ГНС. В этом случае вместо условия (2) следует использовать условие подобия предела хрупкой прочности или текучести, так как именно этот параметр будет определять уровень девиатора гравитационных напряжений:

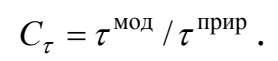

Предел хрупкой прочности пород осадочного чехла $\left(\tau^{\text {прир }}\right)$ с учетом сил сухого - кулоновского - трения и влияния флюидного давления можно оценить величи-

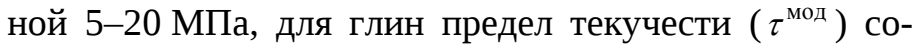
ставляет 0.5-2.0 КПа, что дает значение коэффициента $C_{\tau} \approx 10^{-4}$. Подставляя его в (3) и используя представленные выше значения $C_{L}$ и $C_{\rho}$, находим, что $C_{g} \approx 10$. Отсюда следует, что в экспериментах на глинах, выполняющихся в обычных комнатных условиях, на один порядок занижается вклад в напряженное состояние массовых сил. Для правильного учета вклада ГНС требуется либо применение центрифугирования модели, либо увеличение мощности модельного слоя, т.е. изменение коэффициента $C_{L}$ до значений $10^{-4}$ при $C_{g} \approx 1$. Первый вариант менее эффективен, так как приводит к уменьшению размеров модели $\left(C_{t}=3 \div 5 \cdot 10^{-5}\right)$ из-за небольшого рабочего пространства обычно используемых центрифуг. Второй вариант приводит к мощностям слоя модели 50-100 см при моделировании деформационных процессов в осадочных бассейнах с мощностями 5-10 км и соответствующему увеличению горизонтальных размеров модели до 10-30 размеров мощности слоя.

Для выполнения условия подобия по вкладу в общее напряженное состояние внешних условий нагружения следует использовать выражение (2), которое определяет характерное время моделирования: $C_{t}=10^{-10}$ для $C_{\eta}=10^{-14}$, что требует времени моделирования десять часов для одного миллиона лет в природе. Из приведенного анализа следует существенное увеличение (на порядок) скорости моделирования до значений 30 мкм/сек, отвечающей коэффициенту подобия по скорости $C_{v}=10^{5}$.
Таким образом, понимание того факта, что конечное напряженное состояние и особенности формирования геологических структур зависят от двух факторов воздействия: начального ГНС и внешних сил, действующих на границах геологического объекта (модели), приводит нас к необходимости раздельного анализа коэффициентов подобия по напряжениям для каждого из них (выражения (2) и (5)). Подобное требование вносит больше ограничений на используемые материалы и физические устройства при моделировании. Однако наиболее жестким условием проведения физического эксперимента является требование близости значений коэффициента Пуассона для модельного материала (влажные глины) и горных пород. Для осадочных пород изменение значений коэффициента Пуассона лежит в диапазоне от 0.25 до 0.40 . Существуют определенные трудности при оценке этого коэффициента для влажных глин из-за низкого уровня деформаций в упругой области их деформирования. В силу большого процентного содержания воды можно ожидать, что коэффициент Пуассона влажных глин лишь немногим меньше 0.5, в отдельных случаях приближается к 0.4.

Что произойдет, если в моделях, ориентированных на изучение закономерности и морфологии разрывообразования, не будет выполнено условие по ускорению силы тяжести $\left(C_{g}<10\right.$ при $\left.C_{L}=10^{-5}\right)$ или значение коэффициента Пуассона в модели будут существенно выше, чем в природном объекте, приближаясь к 0.5 ? В этом случае девиаторная компонента начального напряженного состояния, вызываемого только массовыми силами, будет близка к нулю, и влияние ГНС на морфологические параметры хрупких разрывов будет отсутствовать. Поскольку девиатор гравитационных напряжений возрастает с глубиной при нулевых значениях у поверхности модели, различие морфологии трещин в модели и природе будет минимальным у поверхности и существенным в средней и нижних частях модели.

Все рассмотренные обстоятельства указывают на практически непреодолимые трудности, возникающие на пути физического моделирования структур разрушения с использованием влажных глин. Широкие возможности исследования закономерности поля напряжений и структур разрушения для различных механизмов деформирования пород осадочного чехла над активными разломами фундамента создает только математическое моделирование.

\section{3. МАТЕМАТИЧЕСКОЕ МОДЕЛИРОВАНИЕ}

Применительно к рассматриваемой проблеме исследования морфологии хрупких разрывов в глубине зоны горизонтального сдвигания постановка задачи математического моделирования состоит не только в создании модели строения и нагружения исследуемого геологического объекта, но и в учете эволюции его 

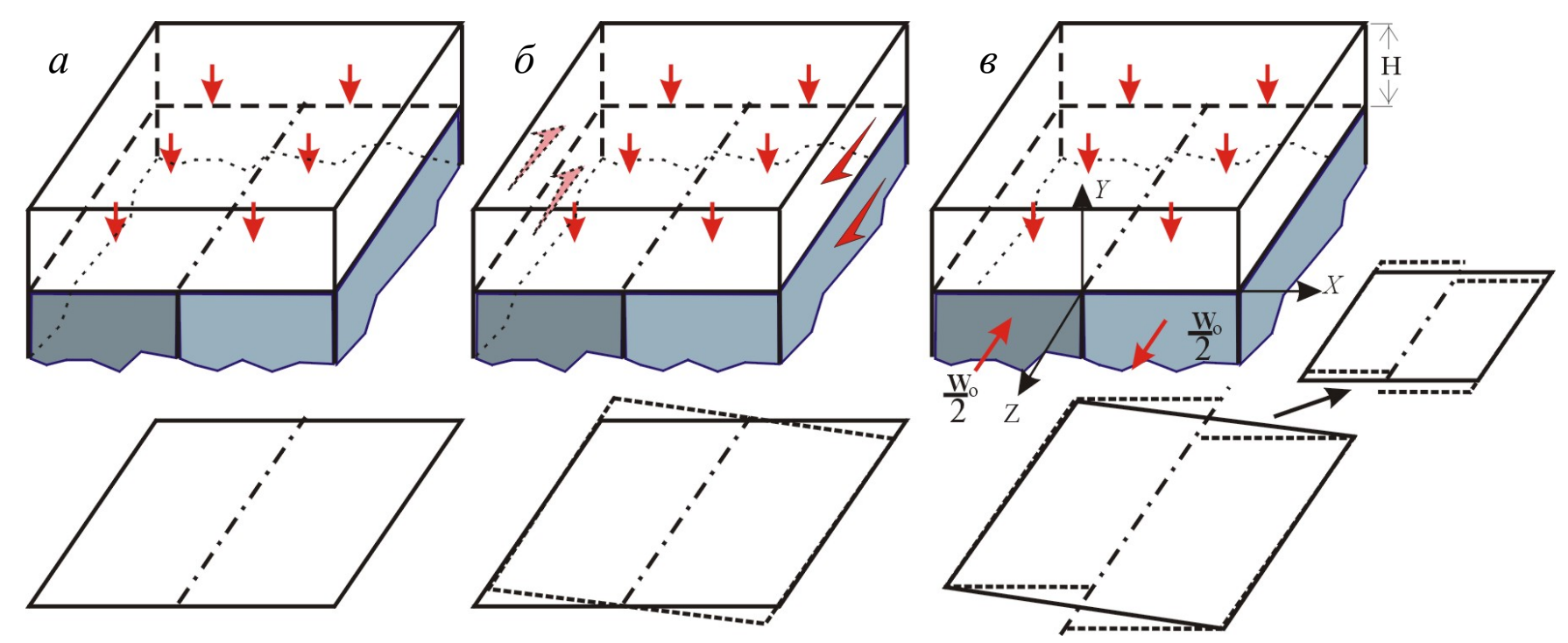

Рис. 2. Схема задачи в эволюции нагружения. $a$ - стадия формирования гравитационного упруго-пластического состояния; $\sigma$ - стадия совместного однородного простого горизонтального сдвига фундамента и чехла (стрелки в торцах модели); в- стадия локализации горизонтального сдвига в слое после относительного смещения блоков фундамента (стрелки показывают направления смещения блоков). Снизу для каждой стадии показано изменение формы основания, штрихпунктирная линия - ось сдвигания, сплошная линия - форма основания до деформирования, пунктирная линия - после деформирования. Пояснения в тексте.

Fig. 2. Loading evolution scheme. $a$ - the stage of formation of gravity elasto-plastic state; $\sigma$ - the stage of simultaneous, similar-type simple horizontal shear of the base and the cover (arrows at the side of the model); $B$ - the stage of localization of horizontal shear inside the layer after displacement of blocks of the base relative to each other (directions of block displacement are shown by arrows). The bottom pictures show changes of the form of the base; chain lines show the axis of shear zone; solid lines show forms of the base before deformation; dotted lines show forms of the base after deformation. Explanations are provided in the text.

нагружения. В рамках такой постановки в качестве геометрической модели объекта будем выбирать слой постоянной мощности, лежащий на полупространстве в виде двух полубесконечных блоков, имеющих между собой плоскую границу контакта (рис. 2). Исследованию подлежит напряженно-деформированное состояние слоя. Будем считать контакт слоя с блоками абсолютным, т.е. исключающим взаимное проскальзывание. Ассоциируя слой с осадочным чехлом, блоки - с кристаллическим фундаментом коры, выберем свойства слоя и блоков для общего случая соответственно в виде упруго-пластического и упругого тела, считая при этом упругие модули и предел прочности блоков минимум на порядок большими. В такой модели деформации блоков являются источником напряжений в вышележащем слое; локальные же деформации самого слоя не способны создать значимых напряжений в блоках. Полагаем слой однородным по плотности и механическим свойствам.

Эволюция условий нагружения обусловлена следующей последовательностью стадий (рис. 2): 1) упруго-пластические деформации слоя (пластичность за счет трещинного течения), вызванные массовыми силами; 2) совместные однородные упруго-пластические деформации слоя и упругие деформации блоков в условиях горизонтального простого сдвигания; 3) упруго-пластические деформации слоя, вызванные гори- зонтальным смещением блоков фундамента друг относительно друга вдоль плоскости их контакта (упругие деформации блоков пренебрежимо малы).

Следует заметить, что до сих пор мы обсуждали только ГНС в качестве начального состояния, предшествовавшего формированию локализованной зоны горизонтального сдвигания. Очевидно, что этапу локализации деформаций, вызванных горизонтальным сдвигом вдоль магистрального разлома фундамента, должен предшествовать этап рассеянной квазиоднородной сдвиговой деформации, которая накладывается на участки геосреды, уже испытавшей необратимые деформации. Также очевидно, что такая квазиоднородная деформация сдвига должна формироваться одновременно в чехле и фундаменте при первичном источнике этих деформаций в последнем (жесткость фундамента выше жесткости пород чехла). Этап локализации деформаций в слое связывается с горизонтальными смещениями блоков его основания, что отвечает формированию хрупкого магистрального разрыва в фундаменте и частичному сбросу накопленных в нем девиаторных напряжений. При этом в слое энергия упругих деформаций и уровень девиаторных напряжений, наоборот, возрастают (до стадии формирования магистрального разрыва), и это связано с перекачкой части энергии упругого деформирования из фундамента в чехол. 


\section{1. СТАДИЯ ГРАВИТАЦИОННОГО НАПРЯЖЕННОГО СОСТОЯНИЯ}

Для анализа начального напряженного состояния (рис. $2, a)$, обусловленного действием только распределенных внутренних массовых сил, можно либо использовать гипотезу чисто упругого деформирования массива [Динник, 1926; Jager, 1962] в условиях горизонтального стеснения $\left(\varepsilon_{x x}=\varepsilon_{z z}=0\right)$ :

$$
\begin{aligned}
& \sigma_{y y}^{e}=-p_{l t}, \sigma_{x x}^{e}=\sigma_{z z}^{e}=-\frac{v}{1-v} p_{l t}, \sigma_{i j}^{e}=0 \text { при } \\
& i \neq j, \quad i, j=x, y, z \quad \text { и } \quad p_{l t}=\rho g(H-Y) \\
& \tau^{e}=\frac{1-2 v}{2(1-v)} p_{l t}, \quad p^{e}=\frac{1+v}{3(1-v)} p_{l t},
\end{aligned}
$$

либо допускать возможность его пластического (катакластического за счет множества трещин) деформирования ниже глубины предельного состояния $H_{p}$ [Ребецкий, 2008a, 2008б, 2009; Rebetsky, 2008]. Если связывать достижение этого предельного состояния с критерием Кулона - Мора

$$
\tau \leq \tau_{f}+k_{f} p^{*} \text { при } p^{*}=p-p_{f l},
$$

то до глубины

$$
\begin{aligned}
& H_{p}=\frac{3(1-v) \tau_{f}}{\left[1.5(1-2 v)-k_{f}(1+v)+3 k_{f}(1-v) \lambda\right] \rho g} \text { при } \\
& \lambda .=p_{f l} / p_{l t},
\end{aligned}
$$

где породы находятся в упругом состоянии, верны выражения (6), а ниже, там, где они пластически деформированы, имеют место дополнительные напряжения горизонтального сжатия $\Delta \sigma$ :

$$
\begin{aligned}
\sigma_{i i}^{g}=\sigma_{i i}^{e}+\Delta \sigma \text { при } i=x, z \text { и } \Delta \sigma= \\
=-\frac{\left\langle 1.5(1-2 v)-k_{f}\langle(1+v)+3(1-v) \lambda\rangle\right\rangle p_{l t}-3(1-v) \tau_{f}}{\left(1.5+2 k_{f}\right)(1-v)},
\end{aligned}
$$

формирующиеся при катакластическом гравитационном уплотнении горных пород.

В представленных выше выражениях $v$ - коэффициент Пуассона, $\rho g$ - средний удельный вес колонки пород (произведение средней плотности на ускорение свободного падения), $\tau_{f}-$ внутреннее сцепление (cohesion), $k_{f}-$ коэффициент внутреннего трения, $\tau=\left(\sigma_{1}-\sigma_{3}\right) / 2-$ максимальное касательное напряжение, $p=\left(\sigma_{x x}+\sigma_{y y}+\sigma_{z z}\right) / 3-$ среднее всестороннее тектоническое давление, $p_{f l}-$ флюидное давление в трещинно-поровом пространстве, обеспечивающее снижение «сухого» трения при сдвиге вдоль трещин [Tepцаги, 1961], $p^{*}$ - эффективное давление, ответствен- ное за сухое трение, $p_{l t}$ - литостатическое давление, равное весу колонки вышележащих горных пород на глубине $H, \lambda$ - коэффициент, характеризующий соотношение флюидного и литостатического давлений, верхний индекс $е$ при напряжениях определяет компоненты ГНС, формирующиеся в чисто упругом состоянии, a $g$ - упруго-пластическом.

Важно отметить, что для упругой области деформирования ГНС и для упруго-пластической области тип тензора напряжений одинаковый, характеризующийся значением коэффициента Лоде - Надаи $\left(\mu_{\sigma}=2\left(\sigma_{2}-\sigma_{3}\right) /\left(\sigma_{1}-\sigma_{3}\right)-1\right)$, равным +1 - одноосное сжатие (мех). Поскольку этому тензору отвечает вертикальная ориентация оси максимальных сжимающих напряжений ( $\left.\sigma_{y y}=\sigma_{3}\right)$, режиму напряженного состояния отвечает горизонтальное растяжение (геол.).

Как следует из (9), ниже границы $H_{p}$ по сравнению с упругим состоянием (6) изменяются только нормальные напряжения в горизонтальном направлении. Величина сжатия в горизонтальном направлении здесь выше, чем это следует из чисто упругой модели. Для значения $v=0.25$ (стандартное значение для горных пород), а $k_{f}=0.6$ (значение коэффициента в образцах консолидированных пород [Byerlee, 1978]) компоненты тензора напряжений чисто упругого состояния и дополнительные сжимающие напряжения, возникающие на стадии пластического деформирования [Ребецкий, 2009], имеют значения:

$$
\begin{aligned}
& \sigma_{y y}^{e}=-p_{l t}, \sigma_{x x}^{e}=\sigma_{z z}^{e}=-0.333 p_{l t}, \\
& p^{e}=0.556 p_{l t}, \tau^{e}=0.333 p_{l t}, \\
& \Delta \sigma \approx-0.667 \lambda p_{l t}+1.11 \tau_{f} \text { при } \\
& H_{p}^{g} \approx 1.67 \frac{\tau_{f}}{\lambda \rho g} .
\end{aligned}
$$

На рис. 3. представлено распределение по глубине максимальных касательных напряжений $\tau$ для упругопластической и чисто упругой $\left(\tau^{e}\right)$ стадий деформирования. Глубина $H_{p}^{g} \approx 0.433$ км отвечает переходу породы в пластическое течение для $\lambda=0.5, \rho g=2.7 \Gamma / \mathrm{cm}^{3}$, $\tau_{f}=3.5$ МПа.

Полученные здесь выражения для начальных напряжений ГНС исходят из мгновенной пластической реакции среды на выполнение критического соотношения (7) в виде равенства. Если считать, что данное напряженное состояние действует достаточно продолжительный период геологического времени и в породах может развиваться ползучее катакластическое течение, обусловленное преодолением длительной прочности, то, полагая в выражениях (9) $\tau_{f}=0$, получим

$$
\sigma_{x x}^{e}=\sigma_{z z}^{e}=-0.333 p_{l t} \text { и } \Delta \sigma \approx-0.668 \lambda p_{l t} .
$$




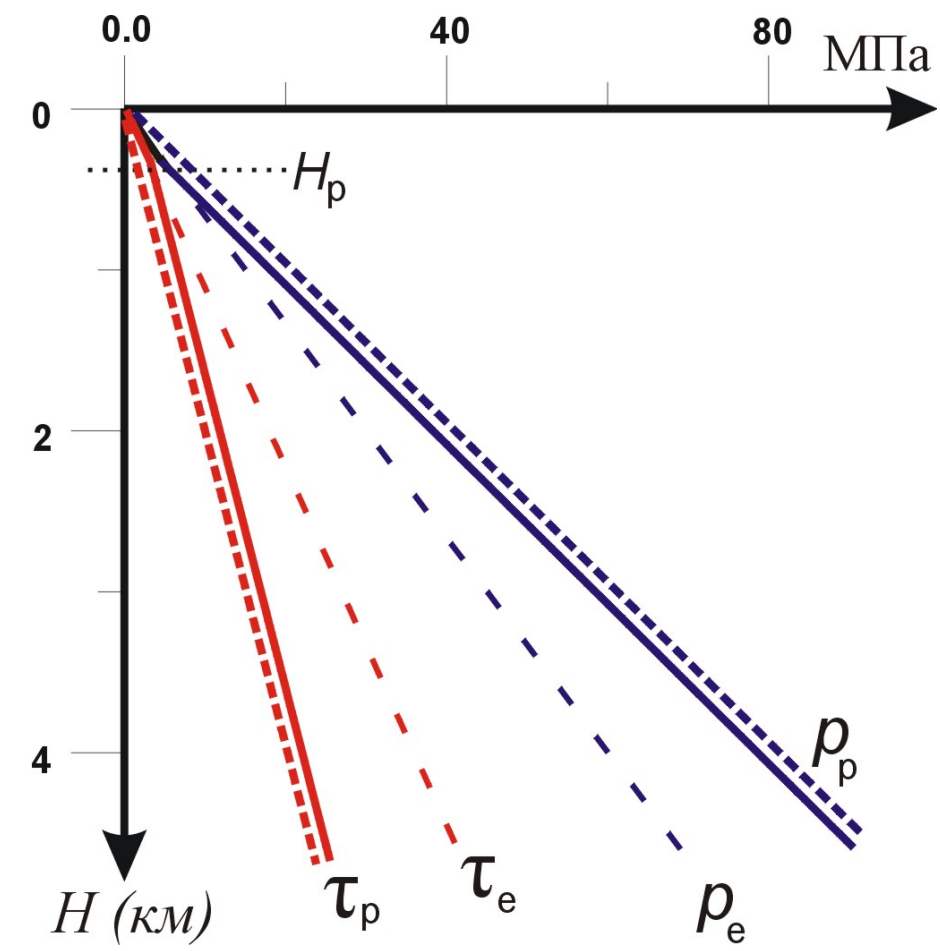

Рис. 3. Изменение по глубине осадочного чехла максимальных касательных напряжений и всестороннего давления для ГНС. Горизонтальный точечный пунктир указывает глубину смены упругого состояния на упруго-пластическое, удлиненный пунктир показывает значения этих параметров для чисто упругого состояния. Значения параметров расчета: $v=0.25, k_{f}=0.6, \lambda=0.5$, $\tau_{f}=0.03$ кбар, $\rho g=2.7 \quad \Gamma / \mathrm{cm}^{3}$ (сплошные линии). Короткий пунктир определяет значения компонент для реологии среды, отвечающей катакластической ползучести $\left(\tau_{f}=0\right)$. Нижний индекс $e$ отвечает компонентам упругого, а $p$ - упруго-пластического деформирования.

Fig. 3. Changes of maximum shear stresses and isotropic pressure with depth for the gravity stress state (GSS). The dotted horizontal line shows depth where the elastic state is replaced by the elastic-plastic state. The long dashed line shows values of the parameters for the pure elastic state. Calculations are done with the following values: $v=0.25$; $k_{f}=0.6 ; \lambda=0.5 ; \tau_{f}=0.03 \mathrm{kbar} ; \rho g=2.7 \mathrm{~g} / \mathrm{cm}^{3}$ (solid lines). The short dotted line shows values of components for the rheology of the medium which corresponds to cataclastic creepage ( $\tau_{f}=0$ ). Index $e$ denotes elastic components; index $p$ denotes elasto-plastic deformation.

При этом гипсометрический уровень начала пластического течения поднимается непосредственно к поверхности $H_{p}^{g}=0$ км.

Напряженное состояние для среды с реологией катакластической ползучести характеризуется зависимостью девиаторных напряжений от всестороннего давления и в общем случае показывает невозможность для ГНС полной релаксации девиаторных напряжений (рис. 3). Заметим, что если флюидное давление с глубиной будет нарастать, то график изменений пред- ставленных компонент тензора напряжений ниже глубины $H_{p}^{g}$ будет нелинейным. Из выражения (10) следует, что только в случае величины флюидного давления, близкой к литостатическому давлению $(\lambda=1)$, девиаторные напряжения практически отсутствуют $\left(\sigma_{x x}=\sigma_{z z} \approx-p_{l t}\right)$. Такая ситуация возможна в осадочных бассейнах до литификации пород и в локальных зонах разломов.

Будем в дальнейшем главные напряжения ГНС записывать в виде:

$$
\sigma_{3}^{g}=-p_{l t}, \sigma_{1}^{g}=\sigma_{2}^{g}=-q p_{l t} .
$$

Здесь верхний индекс определяет источник напряжений, а значение коэффициента бокового отпора (горн. мех.) $q$ зависит от условий деформирования, свойств пород и коэффициента $\lambda$ и в соответствии с выражением (9) может изменяться от 0.33 (для $v=0.25$ ) до 1. Согласно (10) и (11) при указанных выше значениях $\lambda=0.5$

$$
q=-\left(\sigma_{x x}^{e}+\Delta \sigma\right) / p_{l t} \approx 0.667-1.11 \tau_{f} / p_{l t} .
$$

Для $\tau_{f}=3.5$ МПа боковой отпор на глубинах 1 км близок к 0.52 и на больших глубинах увеличивается до 0.67 .

Результаты выполненной оценки закономерности формирования ГНС позволяют говорить о том, что в области ниже границы $H_{p}^{g}$ должны развиваться трещинные деформации, масштаб которых в зависимости от состава и степени литификации пород может изменяться от микроскопического - смещения по границам зерен - до мегаскопического - трещины сантиметровой, метровой длины и более. Поскольку ГНС отвечает тип тензора напряжений - одноосное сжатие, а режиму - горизонтальное растяжение, морфологическому типу трещин будут отвечать крутые сбросы (30-35 от вертикали) при достаточно сильной вариабильности разной ориентировке их простирания в плане. Так как тип тензора необратимых трещинных деформаций должен соответствовать тензору напряжений, т.е. быть близким к одноосному укорочению, можно ожидать, что будут формироваться четыре локальных максимума полюсов этих трещин, сопряженных под $90^{\circ}$.

Важно отметить, что такие сбросы будут иметь наибольшие амплитуды смещений в средней части диапазона глубин $H_{p}^{g}$ - кровля фундамента $(H)$, так как фундамент и порода, лежащая выше глубинного уровня $H_{p}^{g}$ и находящаяся в упругом состоянии, будут препятствовать развитию подобных разрывов (рис. 4). Такое трещинное течение в глубине приводит к тому, что на поверхности слоя-чехла могут практически не наблюдаться заметные вертикальные перемещения. 


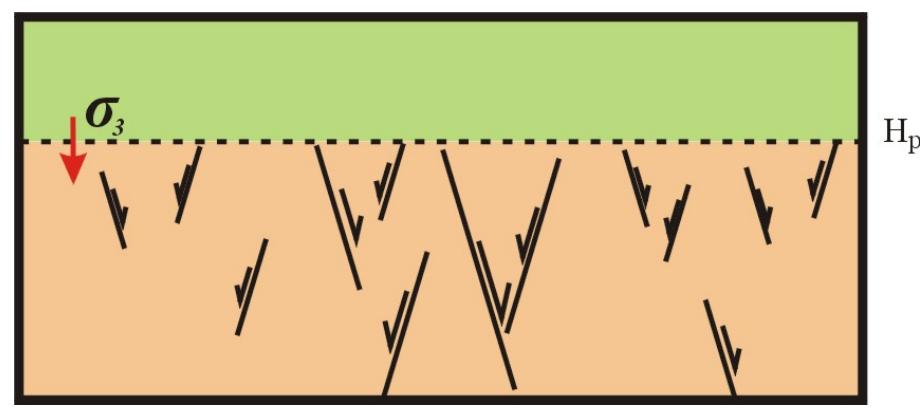

Рис. 4. Схема положения разрывов - сбросов (ниже границы $H_{p}^{g}$ ) в произвольно ориентированном вертикальном сечении для области катакластического течения слоя в условиях ГНС (первая стадия нагружения).

Fig. 4. Locations of normal faults (below $H_{p}^{g}$ boundary) in the arbitrarily oriented vertical profile for the area of cataclastic flow in GSS (the first phase of loading).

\section{2. СТАДИЯ ДЕЙСТВИЯ ОДНОРОДНОГО ГОРИЗОНТАЛЬНОГО СДВИГАНИЯ}

Вторая стадия деформирования модели состоит в добавлении к ГНС дополнительных деформаций горизонтального сдвига $\gamma_{x z}^{s}$. Для данной стадии эти дополнительные деформации предполагаются постоянными как по латерали, так и по глубине (см. рис. 2, б). Результатом такого деформирования будет искажение ранее прямых углов блоков основания, изображенных на рис. 2, б (пунктирный четырехугольник). Поскольку в слое после начальной стадии нагружения имеются области пластического деформирования (ниже границы $H_{p}^{g}$ ), о величинах дополнительных напряжений мы можем сказать только после специально проведенного анализа, представленного ниже. Будем полагать деформации $\gamma_{x z}^{s}$ такими, что максимальное значение дополнительных касательных напряжений, формирующих сдвиг в горизонтальной плоскости (XOZ), $\tau^{s}=2 G \gamma_{x z}^{s}=5$ МПа ( $G$ - модуль упругого сдвига). Это значение касательных напряжений может быть достигнуто тогда, когда все дополнительные деформации являются упругими.

Дополнительные деформации и отвечающие им напряжения есть результат совместного однородного деформирования фундамента и осадочного чехла. Изза разности упругих модулей одинаковые деформации вызывают в кристаллическом фундаменте больший уровень дополнительных напряжений, чем в чехле. Однако существенно меньшая прочность пород последнего приводит к необходимости учета влияния дополнительных напряжений на формирование пла- стических деформаций за счет структур разрушения на долокализационной стадии (второй стадии формирования зоны сдвигания).

При анализе суммарного напряженного состояния для второй стадии деформирования обязательно следует учитывать то, что дополнительные деформации горизонтального сдвига приводят к переиндексации осей главных напряжений в сравнении с их положением для начального ГНС. В рассмотренном для второй стадии случае однородного горизонтального сдвигания эта переиндексация, прежде всего, происходит вблизи поверхности слоя. Здесь ГНС создает низкий (практически нулевой) уровень напряжений и поэтому у поверхности индекс главного напряжения, действующего в вертикальном направлении, будет отвечать промежуточному главному напряжению $\sigma_{y y}=\sigma_{2}^{g s}$ (режим напряженного состояния горизонтального сдвигания - геол.). Главные напряжения $\left(\sigma_{1}^{g s}, \sigma_{3}^{g s}\right)$, действующие в горизонтальном направлении, ориентированы под $45^{\circ}$ к оси сдвигания, поэтому для верхней части слоя выражения для главных напряжений нового состояния определяются следующим образом:

$$
\begin{aligned}
& \sigma_{1}^{g s}=-q p_{l t}+\tau^{s}, \sigma_{2}^{g s}=-p_{l t}, \sigma_{3}^{g s}=-q p_{l t}-\tau^{s} \\
& \text { при } \tau^{s}>0 .
\end{aligned}
$$

Здесь верхний индекс показывает источник нагрузки для каждого из слагаемых ( $g$ - напряжения, обусловленные ГНС, $s$ - напряжения, связанные с горизонтальным сдвиганием), $\tau^{s}$ - дополнительные касательные напряжения, формирующие сдвиг в горизонтальной плоскости. Эти дополнительные напряжения не могут превышать критических значений, определяемых требованием выполнения критерия Кулона Мора (7) для нового напряженного состояния (15). Используя (7) и (15), определим изменения напряжений $\tau^{s}$ с глубиной:

$$
\tau^{s}=\tau_{f}+[(2 q+1) / 3-\lambda] p_{l t} .
$$

Это выражение можно использовать до глубин, где произойдет новая переиндексация главных осей напряжений. После выполнения равенства $\sigma_{2}^{g s}=\sigma_{3}^{g s}$ в нижележащих горизонтах слоя в вертикальном направлении вновь, как и для начального ГНС, действует напряжение максимального сжатия $\sigma_{y y}=\sigma_{3}^{g s}$. Глубина переиндексации $H_{23}^{g s}$ определится выражением:

$$
(1-q) H_{23}^{g s}=\frac{\tau^{s}}{\rho g}
$$

Для использовавшихся выше параметров прочности, флюидного давления и плотности $H_{23}^{g s}=205$ м. Та- 


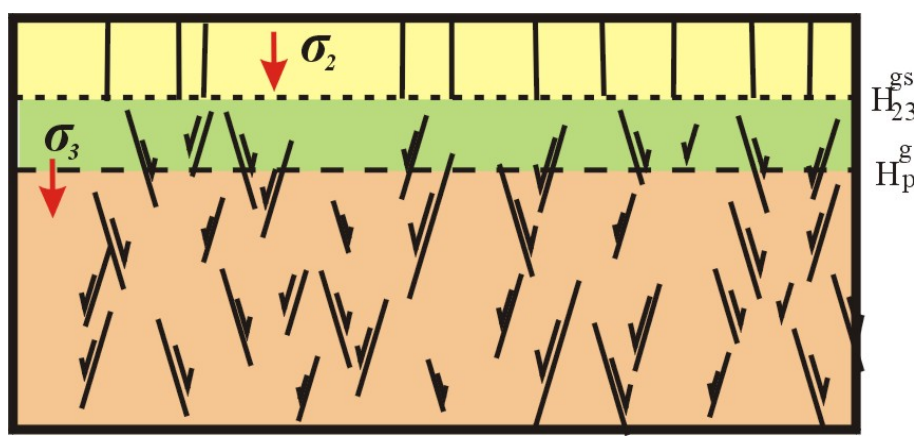

Рис. 5. Схема, показывающая в вертикальном сечении, ориентированном вдоль оси $\sigma_{1}^{g s}$, положения разрывов: сдвигов выше и сбросов ниже $H_{23}^{g} s$, формирующихся в ходе второй стадии нагружения. Ниже границы $H_{p}^{g}$ существуют не показанные на схеме разноориентированные сбросы, возникшие на первой стадии нагружения.

Fig. 5. The vertical profile is oriented along the axis of $\sigma_{1}^{g s}$; locations of strike-slip above $H_{23}^{g s}$ and locations of normal faults below $H_{23}^{g s}$, these faults are formed during the second phase of loading. Below $H_{p}^{g}$ boundary, there are normal faults of various directions that were formed during the first stage of loading; they are not shown in this scheme.

ким образом, в выражениях (16) и (17) при расчетах следует использовать значение коэффициента бокового отпора $q=1 / 3$ (упругое состояние пород для первой стадии нагружения). Согласно (16) на поверхности дополнительные напряжения $\tau^{s}=\tau_{f}=3.5 \mathrm{MПа}$, а на глубине $H_{23}^{g s}$ достигают значения 3.89 МПа. Вид тензора напряжений, определяемый коэффициентом Лоде - Надаи $\mu_{\sigma}$, изменяется от нуля - чистого сдвига (у поверхности) до -1 - одноосного растяжения на глубине $H_{23}^{g s}$.

На второй стадии нагружения выше уровня $H_{23}^{g s}$ вплоть до поверхности породы находятся в состоянии горизонтального сдвигания. Здесь возникают сопряженные субвертикальные трещины скалывания с ориентацией, отвечающей режиму горизонтального сдвига $-R$ - и $R$ ' сколы (рис. 5). Простирание этих трещин соответствует ориентации главных осей девиаторного сжатия и растяжения (15), т.е. отклоняется от оси горизонтального сдвигания и нормали к ней на угол $\varphi_{f}=\arctan \left(k_{f}\right) / 2$ (рис. 6).

Для расчета дополнительных напряжений, возникающих за счет дополнительных деформаций горизонтального сдвига, на глубинах, больших $H_{23}^{g s}$, уже нельзя использовать выражение (16), так как здесь имеет место напряженное состояние с вертикальной ориентацией оси максимального сжатия $\sigma_{3}^{g s}$. В этом состоянии дополнительные деформации горизонтального

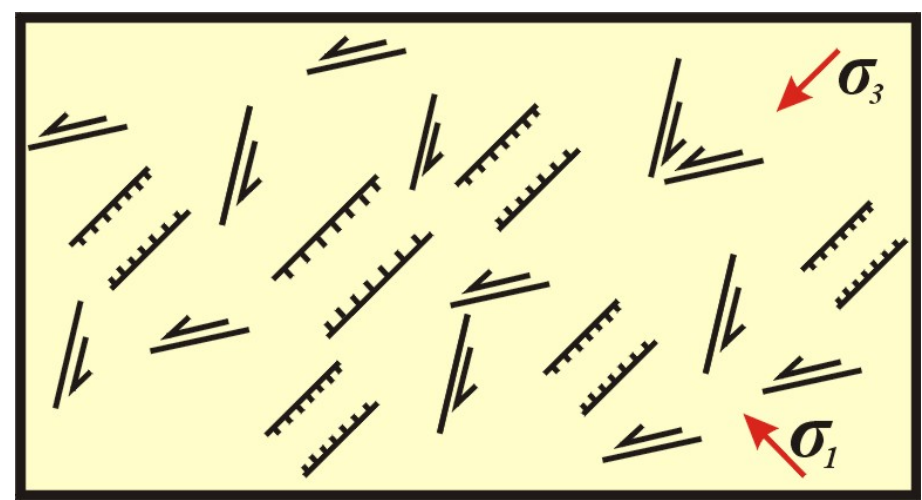

Рис. 6. Сдвиги и сбросы рис. 5 показаны в плане совместно, но по глубине они расположены на разных уровнях. Индексы осей главных напряжений отвечают режиму горизонтального сдвига (область слоя выше уровня $H_{23}^{g s}$ ).

Figure 6. Strike-slip and normal faults shown in Figure 5 are viewed in plan, while at depth they are located at different levels. Indices of principal stress axes correspond to the horizontal shear mode (the area of the layer above the level of $H_{23}^{g s}$ ).

сдвига создают разные по величине упругие деформации в направлении действия главных осей напряжений, ориентированных в горизонтальной плоскости $\left(\sigma_{1}^{g s}\right.$ и $\left.\sigma_{2}^{g s}\right)$.

$$
\begin{aligned}
& \sigma_{1}^{g s}=-q p_{l t}+\sigma_{11}^{s}, \sigma_{2}^{g s}=-q p_{l t}+\sigma_{22}^{s}, \sigma_{3}^{g s}=-p_{l t} \text { при } \\
& \sigma_{22}^{s}=-2 \gamma^{s e} G \geq-(1-q) p_{l t} .
\end{aligned}
$$

Здесь величина дополнительных напряжений $\sigma_{11}^{s}>0$ также может быть определена из условия (7). Она уменьшается от полученного выше значения 3.89 МПа на глубине $H_{23}^{g s}$ до нуля на глубинах, несколько больших $H_{p}^{g}$. Определение глубины нулевого значения $\sigma_{11}^{s}$ также следует из критерия (7). Для всего диапазона глубин, больших $H_{23}^{g s}$, дополнительные деформации горизонтального сдвига приводят к достижению предельных значений критерия (7), что определяет формирование систем сколов в виде сбросов.

Дополнительные напряжения $\sigma_{22}^{s}<0$ для выбранных выше параметров прочности и нагрузок начиная с глубины $H_{23}^{g s}$ возрастают до максимального значения в 5 МПа в силу выполнения для $\sigma_{22}^{s}$ условия (18). Его выполнение следует из самого определения глубины инверсии осей напряжений (17). Важно отметить, что тензор напряжений на глубинах, больших $H_{23}^{g s}$, уже не является тензором одноосного сжатия $\left(\mu_{\sigma}=+1\right)$, как это имело место для первой стадии нагружения, и поэтому новые трещины формируются здесь в виде 
сбросов с простираниями, нормальными к оси $\sigma_{1}^{g s}$ (рис. 6).

Таким образом, в анализируемом слое в результате действия двух этапов нагружения формируется несколько глубинных уровней, различающихся по морфологии систем трещин: верхний $\left(Y>H-H_{23}^{g s}\right)-$ сдвиги (геол.) второго этапа; промежуточный $\left(H-H_{23}^{g s}>Y>H-H_{p}^{g}\right)$ - сопряженная система сбросов с простираниями, параллельными $\sigma_{2}^{g s}\left(45^{\circ}\right.$ к оси сдвигания), второго этапа; нижний ( $\left.H-H_{p}^{g}>Y\right)$ - разноориентированные сбросы первого этапа на фоне сопряженной системы сбросов с простираниями, параллельными $\sigma_{2}^{g s}$ ( $45^{\circ}$ к оси сдвигания), второго этапа.

Согласно выполненному анализу формирующиеся разрывы располагаются в слое квазиоднородно без локализации. Однако вполне вероятно, что на завершающем этапе второй стадии нагружения может происходить некоторая локализация вновь возникающих разрывов. Такая локализация будет связана с изменяющейся проницаемостью в зоне будущего магистрального разрыва в кристаллическом фундаменте, которая будет способствовать локальному повышению флюидного давления в породах осадочного чехла. Следствием этого будет являться более интенсивный перевод упругих деформаций в необратимые через разрывные смещения, из-за чего в чехле над будущим магистральным разломом будет наблюдаться повышенная трещиноватость представленной выше морфологии (рис. 5,6 ). Таким образом, в слое может формироваться латеральное неоднородное деформационное состояние.

В заключении этого раздела заметим, что выполненный здесь анализ упруго-пластической стадии деформирования слоя с начальным ГНС корректен с позиции механики и стал возможен из-за одномерности рассматриваемой проблемы (неоднородность распределения напряжений по глубине). В случаях неоднородных двух- и трехмерных напряженных состояний построение аналитического решения упруго-пластической задачи крайне редко.

\section{3. НАПРЯЖЕННОЕ СОСТОЯНИЕ НЕОДНОРОДНОГО ГОРИЗОНТАЛЬНОГО СДВИГАНИЯ}

Третья стадия деформирования модели отражает формирование в фундаменте разлома со сдвигом по простиранию. В месте его возникновения однородные упругие деформации фундамента трансформируются в разрывные смещения, которые в первом приближении можно считать постоянными, практически не изменяющимися вкрест оси сдвига. Формируется тип смещений, подобный тому, что предложил Х. Рэйд [Reid, 1910] для объяснения трансформации накопленных упругих деформаций в смещения в очаге землетрясения. В более общем случае такой механизм также воз- можен и для медленных горизонтальных перемещений вдоль разлома. Здесь добавочные напряжения, возникающие на развитом этапе третьей стадии, будут рассчитаны на основе модели нагружения, представленной на рис. 2, в. В этой модели скошенный четырехугольник блока основания разбивается на два блока в виде прямоугольных четырехугольников (пунктирные линии). Деформации слоя, получаемые в процессе разрывного смещения блоков фундамента, суммируются с деформациями предыдущих стадий нагружения. Часть этих деформаций слоя необратимые, а часть упругие, вызывающие изменение напряженного состояния. Корректное решение подобной задачи в упругопластической постановке с учетом начального напряженного состояния двух предыдущих стадий нагружения достаточно сложное, требует привлечения численных методов. Здесь мы воспользуемся приближенным анализом, используя ранее полученное решение задачи антиплоской деформации слоя на двух смещающихся блоках основания [Ребецкий, 1987; Rebetsky, 1988]. Фактически это означает, что вместо конфигурации блоков основания на конечной стадии, показанной на рис. 2, в, будет иметь место конфигурация блоков основания уменьшенной схемы (по стрелке). Такая замена условий на подошве слоя приводит к тому, что в слое вблизи оси сдвигания решение будет близко к требуемому исходной постановкой задачи. На некотором удалении от оси отклонение в получаемом решении будет связано с отсутствием учета напряжений однородного горизонтального сдвигания второй стадии нагружения.

В рамках постановки такой задачи антиплоской деформации наша модель на третьей стадии нагружения представляет собой бесконечно плоский однородный по свойствам слой, лежащий в условиях полного сцепления без возможности проскальзывания на двух полубесконечных жестких блоках - основание модели (в природе блоки кристаллического фундамента), которые горизонтально смещаются вдоль плоской границы их контакта (в природе разлом), бесконечной вдоль оси $Z$ и с ней совпадающей при $Y=0$ (см. рис. 2). Верхняя поверхность слоя свободна от нагружения, а на бесконечности напряжения, вызванные сдвиганием жестких блоков, нулевые (здесь действуют только ГНС). В такой модели в плоскостях, ориентированных перпендикулярно оси $Z$, характер напряженного состояния один и тот же, а относительное смещение блоков основания как целого амплитуды $w_{0}$ происходит параллельно оси сдвигания.

В реальности разлом фундамента редко бывает плоским и всегда конечен в латеральном направлении. Небольшие отклонения разлома от плоского вида создают малые вариации напряжений, и ими можно пренебречь. Большие изгибы разлома горизонтального сдвигания должны специально учитываться при моделировании. Ограниченность длины разлома предопределяет отклонение напряженного состояния нашей 


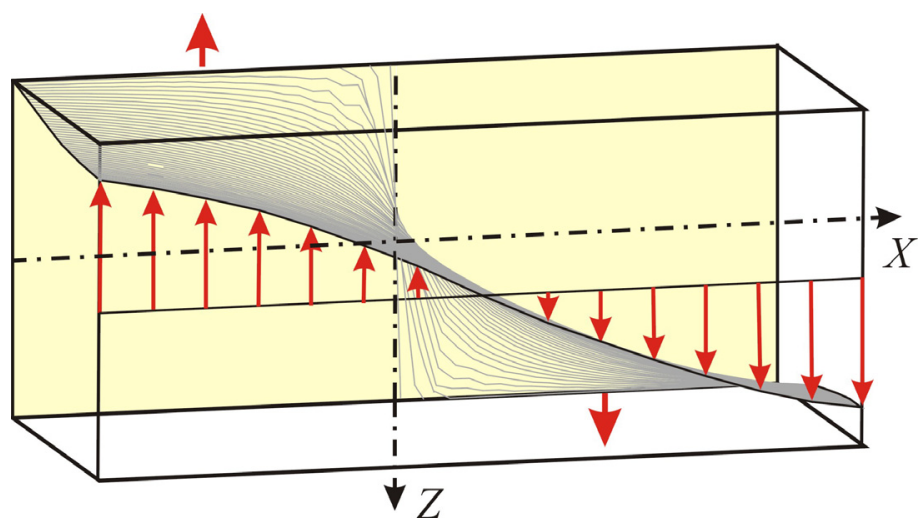

Рис. 7. Деформации плоскости вертикального сечения в модели неоднородного по глубине простого сдвига (аксонометрия, вид сверху), длина тонких стрелок показывает относительную амплитуду горизонтальных смещений вдоль оси сдвигания на поверхности слоя, жирные стрелки показывают направление смещения блоков фундамента.

Fig. 7. Deformations of the plane of the vertical profile in the model of simple shear which is heterogeneous in depth (axonometric, top view). Lengths of thin arrows show relative amplitudes of horizontal displacement along the axis of the shear zone on the layer's surface; directions of displacement of blocks of the base are shown by thick arrows.

бесконечной в плане модели от конечного идеализированного геологического объекта, но эти отклонения в соответствии с эффектом Сен-Венана будут приходиться на область вблизи концов разлома с характерным размером не более мощности слоя и много меньше длины разлома [Надаи, 1954]. В силу последнего обстоятельства поле напряжений, полученное в нашей модели, будет соответствовать напряжениям в слое над сдвиговым разломом фундамента практически всюду за исключением его концевых участков.

Как показано в работах [Ребецкий, 1987; Rebetsky, 1988], в модели, отвечающей геометрии и условиям нагружения рис. 2, $B$, возникает неоднородное напряженное состояние не только по латерали, но и по глубине. Подобная неоднородность определяет изменение ориентации осей главных напряжений в объеме модели, что влечет за собой смену типа напряженного состояния. Поскольку в указанных работах исследования выполнялись в предположении идеально вязкой модели среды, в которой ГНС не приводит к формированию девиаторных напряжений, ниже будет дана постановка и решение задачи для упруго-пластической модели среды.

Решение задачи для упругого слоя, находящегося в условиях нагружения рис. 2, в, дает выражение для смещения вдоль оси $Z$ [Ребецкий, 1987; Rebetsky, 1988] следующего вида:

$$
w=\frac{w_{0}}{\pi} \operatorname{arctg} \frac{\operatorname{sh}(\pi X / 2 H)}{\sin (\pi Y / 2 H)},
$$

где $w_{0}$ - относительная амплитуда смещения жестких пластин подложек (блоков фундамента). На рис. 7 представлена схема деформирования вертикальной плоскости за счет горизонтальных смещений (19).

Если анализировать напряженное состояние в идеальной упругой среде, обусловленное только движениями блоков основания (рассматривается задача при отсутствии ГНС), то оно определяется касательными напряжениями $\sigma_{x z}^{s}$ и $\sigma_{y z}^{s}$ :

$$
\begin{aligned}
& \sigma_{x z}^{s s}=\mu \frac{\partial w}{\partial x}=\frac{w_{0} \mu}{H} \frac{\sin (\pi Y / 2 H) \operatorname{ch}(\pi X / 2 H)}{\operatorname{ch}(\pi X / H)-\cos (\pi Y / H)}, \\
& \sigma_{y z}^{s s}=\mu \frac{\partial w}{\partial y}=-\frac{w_{0} \mu}{H} \frac{\cos (\pi Y / 2 H) \operatorname{sh}(\pi X / 2 H)}{\operatorname{ch}(\pi X / H)-\cos (\pi Y / H)},
\end{aligned}
$$

где $\mu$ - модуль упругого сдвига. Представленные выше выражения определяют вклад в общее напряженное состояние участка коры от горизонтального сдвигания блоков его кристаллического фундамента. Другие компоненты тензора напряжений для этого воздействия нулевые.

Согласно выражениям (20) интенсивность девиаторных напряжений возрастает по мере приближения к оси сдвигания, достигая своего максимума у подошвы над линией контакта блоков фундамента (разлом) (рис. 8). Важно отметить, что рассматриваемое напряженное состояние не создает вклад в значение всестороннего давления, так как является чистым сдвигом в механическом понимании этого термина - главные алгебраически максимальное и минимальные напряжения равны друг другу по модулю, а промежуточное главное напряжение равно нулю.

На рис. 9 представлен в трехмерном виде характер траекторий двух главных напряжений $\sigma_{1}$ и $\sigma_{3}$, отражающий сложный двухмерный тип напряженного со-

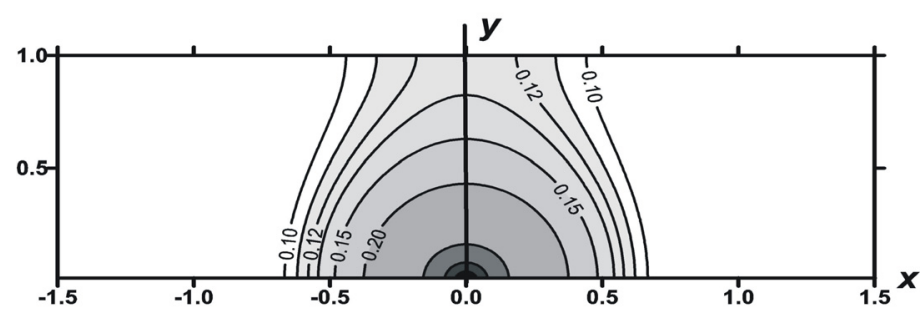

Рис. 8. Области разной интенсивности значений максимальных касательных напряжений в модели неоднородного простого сдвига без учета начального ГНС. Значения напряжений обезразмерены на $w_{0} \mu / H$.

Fig. 8. Areas of various intensities of maximum shear stresses in the model of heterogeneous simple shear (initial HSS is not taken into account). Stress values are dimensionless by $w_{0} \mu / H$. 


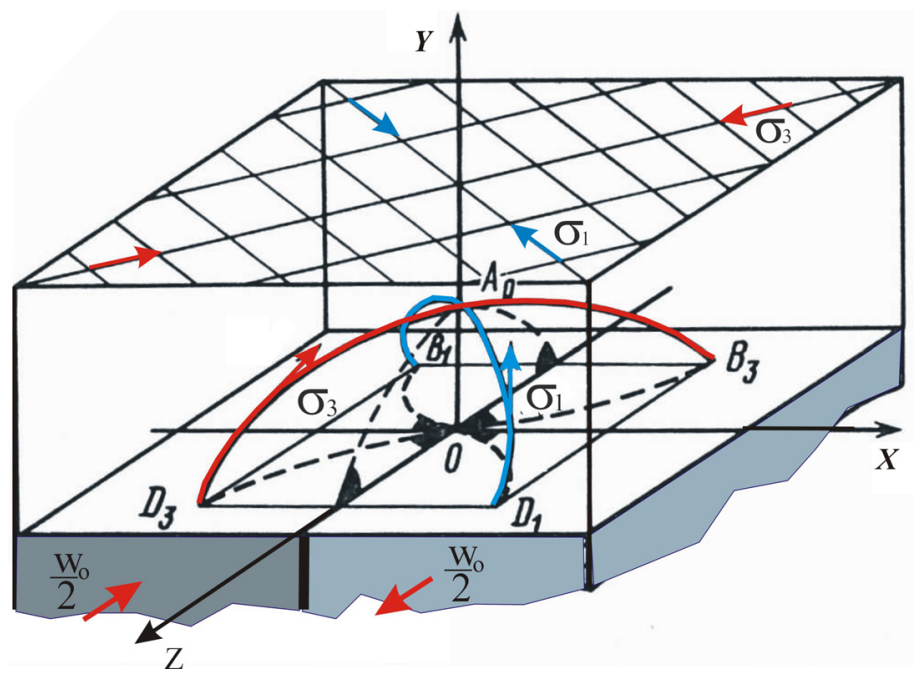

Рис. 9. Траектории осей главных напряжений $\sigma_{1}$ и $\sigma_{3}$ (сплошные линии) внутри слоя без учета начального ГНС (точки $D_{i}, B_{\mathrm{i}}, i=1,3$ - точки входа и выхода осей из подошвы слоя, а точка $A_{0}$ - точка пересечения траекторий с осевой плоскостью сдвига), пунктир проекции траекторий главных напряжений на вертикальную и горизонтальные плоскости. На поверхности траектории осей главных напряжений вырождаются в два семейства ортогональных линий, составляющих осью сдвига угол в $45^{\circ}$.

Fig. 9. Trajectories of principal stress axes, $\sigma_{1}$ and $\sigma_{3}$ (solid lines) inside the layer (initial HSS is not taken into account). Points $D_{i}, B_{\mathrm{i}}, i=$ 1,3 show inlets and outlets of the axes from the layer's foot. $A_{0}$ shows the point wherein the trajectories are crossing the axial plane of the shear zone. The dotted line shows projections of principal stress axes' trajectories to the vertical and horizontal planes. On the surface, the principal stress axes' trajectories are degenerated into two sets of orthogonal lines (their angle to the axes of the shear zone is $45^{\circ}$ ).

стояния (ориентация осей не зависит от координаты $Z$ ). В каждой точке слоя оси этих главных напряжений лежат в плоскости, параллельной оси сдвигания. Такое их положение связано с тем, что оси $\sigma_{2}$ всегда лежат в плоскости, параллельной $X O Y$. Вблизи кровли слоя ориентация осей $\sigma_{1}$ и $\sigma_{3}$ показывает наличие здесь режима горизонтального сдвига (оси в горизонтальной плоскости по углом $45^{\circ}$ к оси сдвигания), а вблизи подошвы - режима взреза или поддвига, когда эти оси лежат в вертикальной плоскости с углами погружения $45^{\circ}$. Если находиться прямо над осью сдвига, то здесь режим напряженного состояния такой же, как у поверхности, - горизонтального сдвига, но уже при небольшом латеральном отклонении от оси режим напряженного состояния начинает быстро изменяться.

\section{4. СОВМЕСТНОЕ ДЕЙСТВИЕ ГРАВИТАЦИОННОГО НАПРЯЖЕННОГО СОСТОЯНИЯ И СОСТОЯНИЯ НЕОДНОРОДНОГО ГОРИЗОНТАЛЬНОГО СДВИГАНИЯ}

Для прогноза морфологии хрупких разрывов на третьей стадии нагружения (рис. 2, в, в приближении конфигурации блоков малой схемы) конечное напряженное состояние будем считать близким к простой сумме гравитационных напряжений (12) и напряжений, вызванных смещением блоков (20):

$$
\begin{aligned}
& \sigma_{y y}=-p_{l t}, \sigma_{x x}=\sigma_{z z}=-q p_{l t}, \sigma_{x z}=\sigma_{x z}^{s s}, \\
& \sigma_{y z}=\sigma_{y z}^{s s}, \sigma_{x y}=0 .
\end{aligned}
$$

Такое предположение, конечно, следует рассматривать как определенное приближение, но оно позволяет уловить основную закономерность, связанную с ненулевой девиаторной компонентой ГНС. В действительности необходимо решать упруго-пластическую задачу, как это делается в работах по численному моделированию (например [Стефанов, 2005]). Такое решение приведет к отклонению компонентов напряженного состояния от значений, следующих из выражений (21), из-за достижения напряжениями критических значений (7), но эти отклонения не должны привести к принципиальным изменениям анализируемого напряженного состояния.

Параметры суммарного напряженного состояния (21) позволяют найти ориентацию осей главных напряжений и на их основе в соответствии с теорией Кулона - Мора дать прогноз положения вторичных нарушений на поверхности и в глубине модели так, как это делалось в работе [Осокина, 1987]. В нашем прогнозе оба сопряженных скола, формирование которых возможно там, где достигнуто критическое значение кулоновых напряжений, являются равноправными. В природе и в эксперименте в зависимости от механических свойств конкретных материалов и способа нагружения могут реализоваться как обе, так и только одна из систем сколовых трещин. Эксперименты на моделях из влажных глин в условиях горизонтального сдвигания показывают [Стоянов, 1977; Бокун, 1991; Bokun, 2009; Гинтов, 2005], что $R$ '-сколы, близортогональные к оси сдвигания, формируются первыми и на последующей стадии при возникновении $R$-сколов не появляются.

В расчетах коэффициент внутреннего трения $k_{f}$, определяющий значение угла скалывания, как и раньше, принимался равным 0.6, что формирует отклонение плоскостей скола от плоскостей максимальных касательных напряжений в сторону оси наибольшего сжатия на угол в $15.5^{\circ}$. Коэффициент бокового отпора $q$ ГНС принимался одинаковым по глубине, равным 0.8.

На рис. 10 приведены результаты прогнозного расчета ориентации плоскостей хрупкого скола для шести глубинных уровней в точках, лежащих на одной вертикали, отстоящей на расстоянии $X=0.1 H$ от оси сдвигания. Непосредственно вблизи поверхности модели $\left(Y=0.99 H\right.$ ) оси главных напряжений $\sigma_{1}$ и $\sigma_{3}$ субгоризонтальны (длинные проекции осей), а ось промежуточного главного напряжения $\sigma_{2}$ субвертикальна. 

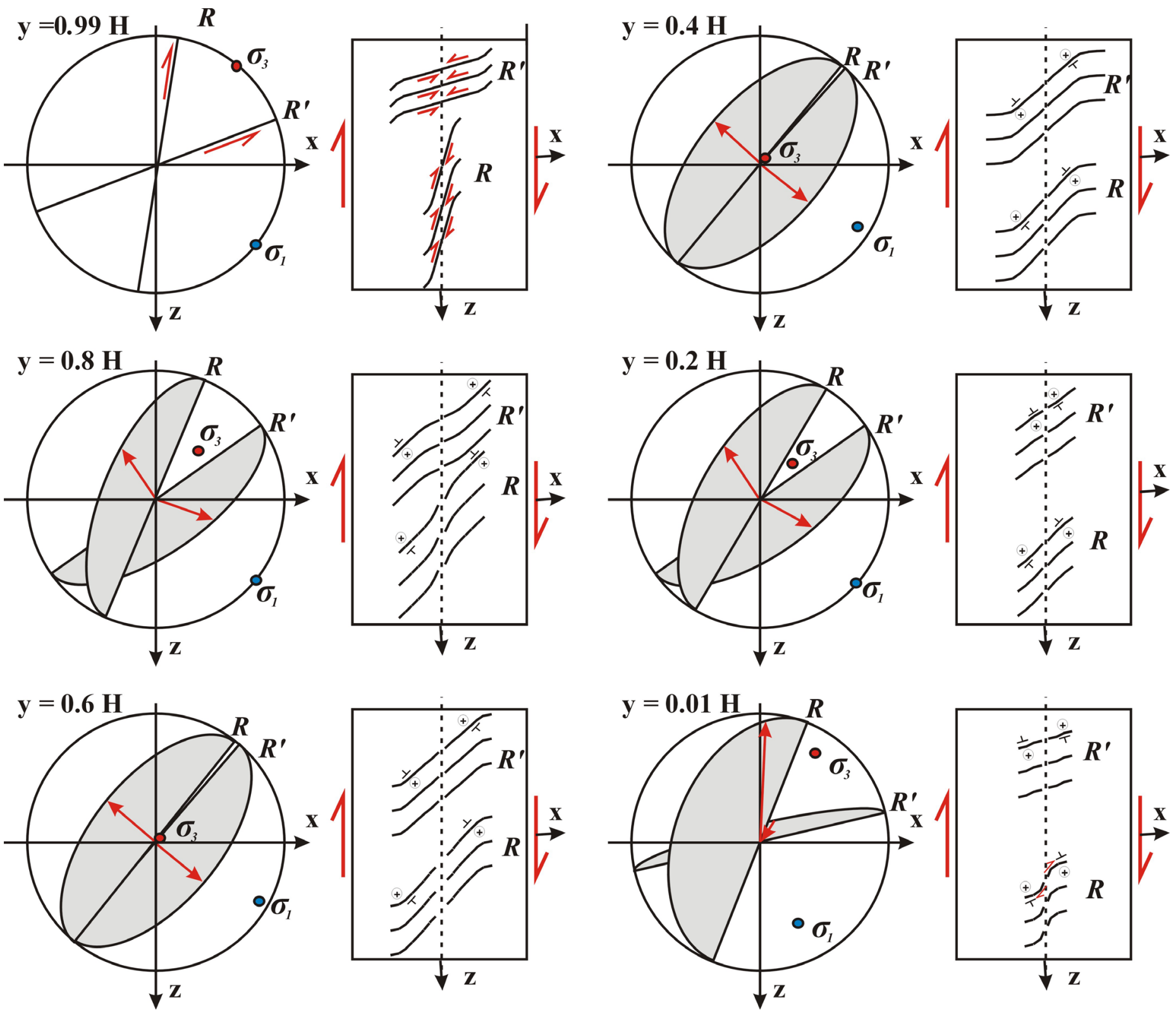

Рис. 10. Ориентация главных напряжений и площадок скалывания вблизи оси сдвигания $(X=0.1 H)$ для разных глубин в проекциях на нижнюю полусферу и прогноз изменения положения простирания плоскостей сколов на удалении от оси сдвигания (поднятое крыло скола обозначено + , а направление погружения плоскости $-\perp$ ) для суммарного напряженного состояния от действия массовых сил и горизонтального движения блоков основания.

Fig. 10. Orientations of principal stresses and shear fracturing in the vicinity of the axes of shear zone $(X=0.1 H)$ for various depths in the projections to the lower semi-sphere, and forecasted changes of the strike of the shear planes at a distance from the shear axis. The raised wing of the shear is marked by +; the plane's dip is shown by ${ }^{\perp}$ ) for the state of total stress from mass forces and horizontal movement of blocks of the base.

Обе плоскости скалывания субвертикальны, и одна из плоскостей $(R$-сколов) составляет с осью сдвига более острый угол, чем другая ( $R$ '-сколов). Здесь обе системы трещин представляют собой сдвиги и влияние девиаторной компоненты тензора гравитационных напряжений практически отсутствует. Трещины, развивающиеся вблизи поверхности, но на небольшом от нее удалении ( $Y=0.8 H$ ), уже не вертикальны. Погружение $R$-сколов для всего диапазона глубин направлено в сторону оси сдвигания. С глубиной плоскости $R$ - и $R^{\prime}$-сколов разворачиваются, так что их простирания начинают постепенно сближаться, а угол погружения - уменьшаться. Вблизи оси сдвигания на глубине $Y=0.7 H$ углы между простиранием этих сколов менее $20^{\circ}$, а ось максимального сжатия имеет угол погружения больше $70^{\circ}$.

Характерным является то, что для обеих систем сколов наблюдается существенная сбросовая компонента смещения при резком уменьшении величины сдвига по простиранию. Для глубины $Y=0.9 H$ они 
практически равны друг другу, а на глубине $Y=0.7 H$ компонента сброса превышает 90 \% от общего значения смещения бортов трещины. В средней по глубине части слоя простирания обеих систем сколов практически параллельны друг другу. Здесь влияние ГНС на общее напряженное состояние максимально. Еще глубже, начиная с $Y=0.3 H$, простирания плоскостей скалывания вновь начинают расходиться, меняется угол погружения каждой из систем сколов, а ось максимального сжатия постепенно становится более пологой. Начиная с этих глубин вновь проявляется влияние напряжений, вызываемых горизонтальным движением блоков фундамента, которое резко ослабевает по мере удаления от осевой плоскости зоны сдвигания. Вблизи подошвы фундамента $(Y=0.01 H)$ на очень небольшом удалении от оси сдвигания $(X=0.01 H)$ оси алгебраически максимального и минимального главных напряжений имеют углы погружения около $40^{\circ}$, а их простирания отклонены от оси сдвигания на углы менее $35^{\circ}$. При приближении к оси сдвигания (дополнительные расчеты выполнялись для $X=0.05 H$ ) влияние сдвигового режима становится все более существенным.

Возникающие на последней стадии нагружения системы трещин (рис. 10) накладываются на ранее созданные системы трещин, которые также могут частично активизироваться, меняя свой кинематический тип. Суммируя все стадии формирования трещин, можно сказать, что проведенные исследования показали важную роль в закономерности их возникновения в горном массиве эволюции (последовательности) его нагружения. Установлено, что в слое, испытывающем на конечной стадии деформирования локализованный горизонтальный сдвиг, морфология разрывов, возникающих на разных глубинных уровнях, будет достаточно многообразна. В верхних горизонтах повсеместно будут встречаться сопряженные системы сколов Риделя субвертикальной ориентации, возникновение которых, согласно проведенному нами моделированию, прогнозируется на второй и третьей стадиях нагружения. В зоне над разломом фундамента плотность этих разрывов растет.

Напомним, что наш прогноз не позволяет выявить одну из двух сопряженных пар сколов, развитие которой в данных условиях нагружения и свойств материала предпочтительно, поэтому мы представляем результаты анализа для обеих систем трещин. Наши расчеты показывают, что для небольших глубин по мере удаления от оси сдвигания происходит разворот простирания плоскостей скалывания, они становятся субпараллельными друг другу. Таким образом, в плане трещины одной системы для обоих бортов зоны сдвигания принимают $S$-образную форму. Этот разворот определяется уменьшением влияния напряжений, вызываемых смещением блоков основания (фундамента), на суммарное напряженное состояние. В этом случае роль девиатора гравитационных напряжений стано-

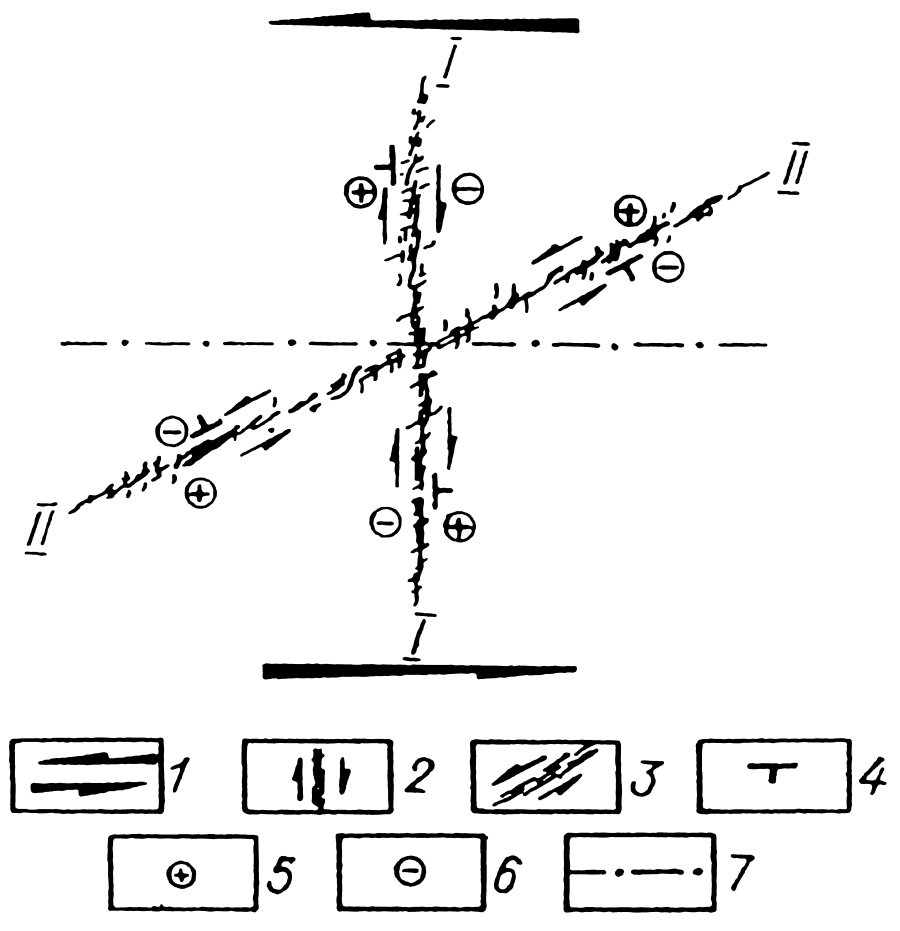

Рис. 11. Схема разрушения поверхности модели из влажной глины для неоднородного по глубине простого сдвига с системами $R$ сколов (II) и $R^{\prime}$-сколов (I) по результатам экспериментов [Борняков, 1981]. 1 - направления сдвига модели; 2-3- $R$ и $R$ '-сколы; $4-$ направления наклона плоскости скола; 5-6- поднятое и опущенное крылья систем сколов; 7- ось сдвигания.

Fig. 11. Schematic view of deformation of the wet clay model's surface in case of simple shear which is heterogeneous with depth, with systems of $R$ (II) and $R^{\prime}$ shears (I) according to physical modeling results published in [Борняков, 1981]. 1 - directions of model's displacement; $2-3$ - $R$ and $R$ ' shears; 4 - inclination of the shear plane; 5-6- raised and lowered wings of the shear systems; 7 - the axes of shear zone.

вится определяющей. Поскольку это состояние соответствует горизонтальному растяжению, в этой части сколов относительно общей амплитуды увеличивается компонента сброса в смещениях его бортов.

В работе С.А. Борнякова [1981] на влажных глинах подтвержден факт наличия на поверхности моделей небольшого наклона плоскости трещины $R$-сколов в направлении против смещения подложек, наблюдавшийся также в экспериментах [Парфенов, Жуковский, 1966]. Показано, что эти сколы помимо сдвиговой имеют и вертикальную компоненту смещений: сбросовую для $R$-сколов и взбросовую для $R$ '-сколов (рис. 11). Плоскость трещин в месте пересечения с осью сдвиговой зоны принимает вертикальное падение, а на удалении падение выполаживается до углов 75-80 ${ }^{\circ}$ от вертикали с направлением погружения в сторону направления подложек. Подобная конфигурация трещин в разных бортах зоны сдвигания определяет их общую пропеллерообразную изогнутость при переходе через ось сдвигания. Характер вертикального 
$a$

Нодальная плоскость

Простирание

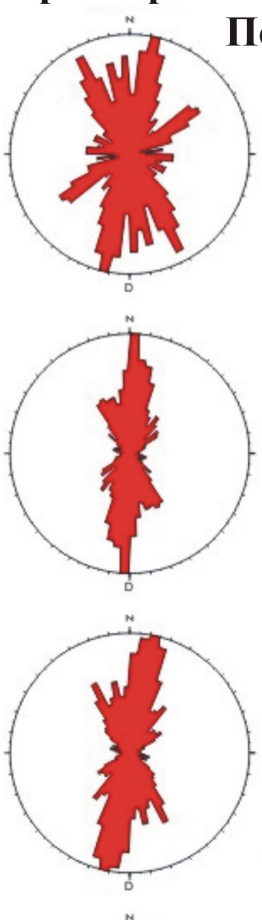

Погружение
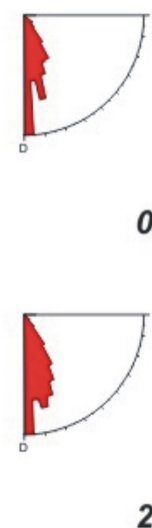

$0.22 m$

Простирание

\section{Вектор смещения}
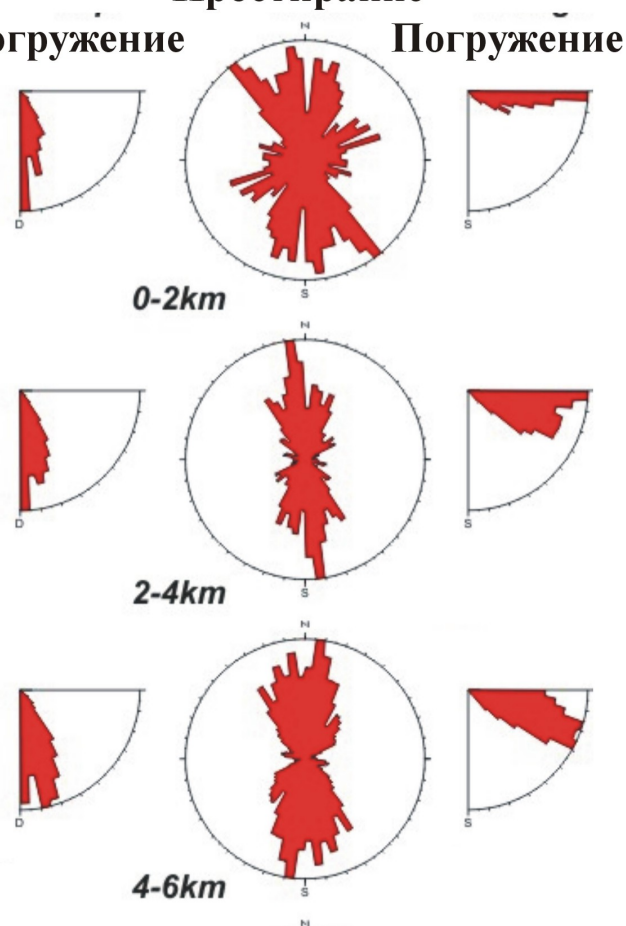

Нодальная плоскость

Простирание

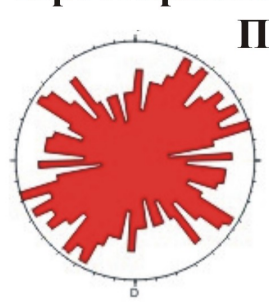

Погружение
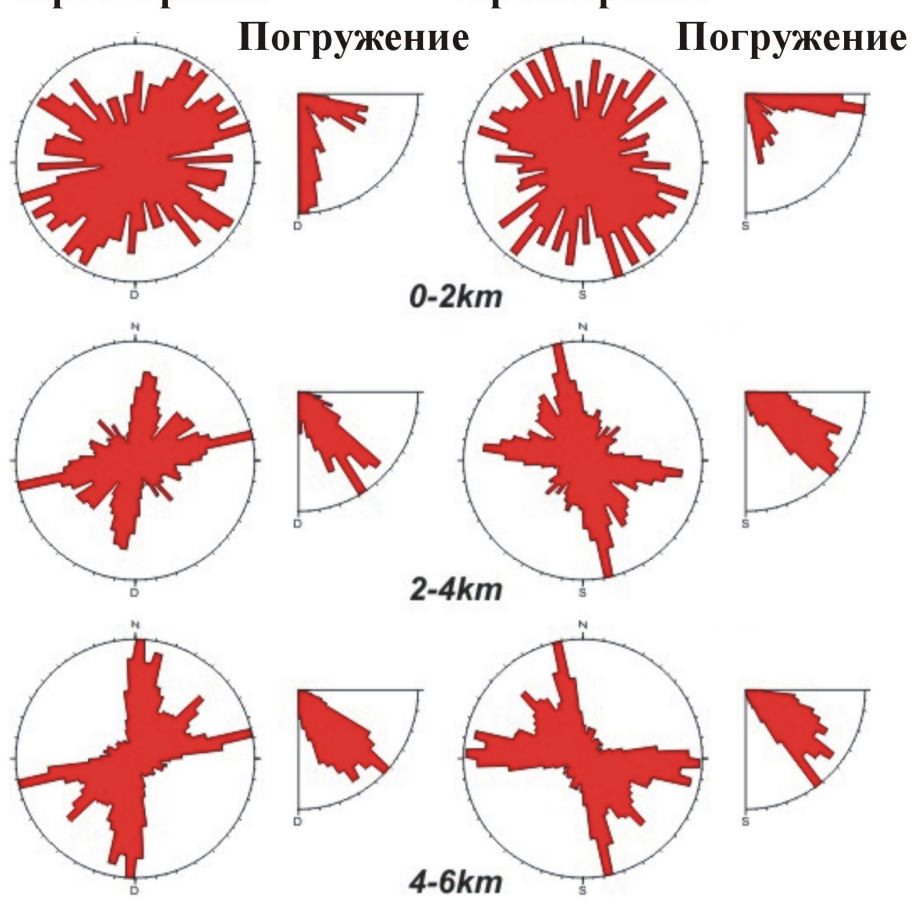

\section{Вектор смешения}

\section{Простирание}

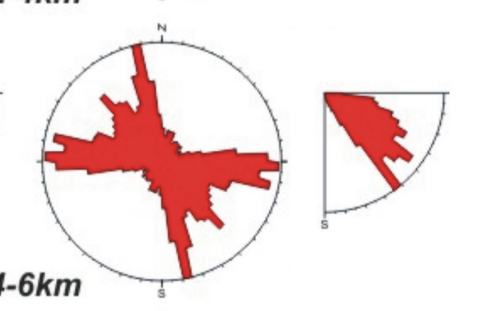

Рис. 12. Положение нодальных плоскостей и векторов смещений по ним для механизмов очагов землетрясения в виде двойного диполя с выраженной правосдвиговой компонентой смещения (а) и нормальным сбросом (б). Рисунки предоставлены Ж. Анжелье. Пояснения в тексте.

Fig. 12. Positions of nodal planes and their displacement vectors for earthquake focal mechanisms represented by a double couple with manifested right-side displacement component $(a)$ and normal fault (б). Figures are provided by J. Angelier. See explanations in the text.

смещения крыльев трещин характеризует $R$-сколы как сдвиги со взбросовой компонентой смещений, а $R^{\prime}$ сколы как сдвиги со сбросовой компонентой смещений. Этот важный факт остался практически незамеченным другими экспериментаторами и нашел свое подтверждение в результатах математического моделирования, представленного на рис. 10. Заметим, что пропеллерообразность сколов обоих бортов зоны сдвигания соответствует наблюденным данным 3Dсейсмики [Гогоненков и др., 2007]. Если сопоставить прогнозируемые нами сколы с данными о механизмах очагов землетрясений Южной сейсмической зоны Исландии, которая является правосторонним сдвигом по субмеридиональным разломам [Angelier et al., 2008] (рис. 12, a), то можно увидеть, что в природной зоне горизонтального сдвигания уже в самых верхних слоях (глубины менее 2 км) плоскости сдвигов не абсолютно вертикальны, а с глубиной их максимум погружения сначала приближается к $15^{\circ}$ (2-6 км), а затем к 30-40 (глубже 6 км). Простирание этих нодальных плоскостей отклоняется от оси сдвигания на угол 10-15․ Для глубин 4-6 км этим механизмам землетрясений отвечает сдвиг с достаточно существенной сбросовой компонентой. Эти данные очень хорошо соответствуют результатам нашего прогноза (см. рис. 10).

Сейсмические данные показывают также достаточно большое число механизмов с превалирующей сбросовой компонентой (рис. 12, б). Наклон нодальных плоскостей, отвечающих этим сбросам, на глубинах более 2 км приближается сначала к 30, а затем и к $45^{\circ}$. Эти сбросы для глубин более 2 км соответствуют прогнозу рис. 10, их также можно рассматривать как разрывные структуры, которые сформировались на стадии подготовки и в современную эпоху вновь активизируются. Важно также отметить, что прогнозируемая согласно нашим расчетам форма поверхности $R$ сколов, развивающаяся по всей глубине зоны сдвигания обоих ее крыльев, в большей части мощности слоя совпадает с формой, приведенной в работе [Sylvester, 1988] (см. рис. 1, б). Ее построение Г. Сильвестер объяснил необходимостью совместить простирание этих сколов на поверхности модели и ориентацию сдвига 
блоков фундамента. Различия наблюдаются в самой нижней части слоя вблизи фундамента. Заметим, что имеет место разворот трещин и в нашем прогнозе простирание $R$-сколов не совпадает с осью сдвигания так, как это имеет место в модели Г. Сильвестера. Можно предположить, что в реальных материалах вблизи фундамента может происходить заложение трещин типа $L$-сколов так же, как это наблюдается в экспериментах на глинах вблизи поверхности.

Если на основании результатов физических экспериментов считать, что развитая стадия горизонтального сдвигания дает преимущество для формирования $R$ сколов, то тогда можно сказать, что поверхность системы $R$-сколов (поверхность, в каждой точке которой плоскости ее отдельных сколов параллельны) сверху вниз испытывает изгиб от субвертикальной приповерхностной $(Y>0.6 H)$ через круто наклоненную в средней части ( $0.6 H>Y>0.2 H)$ и вновь субвертикальную прифундаментную в осевой зоне сдвигания. Если совместить поверхности $R$-сколов для обоих бортов в глубине зоны горизонтального сдвигания, то она будет представлять собой пропеллер. Такая ориентация поверхности образующихся разрывов очень хорошо соответствует данным рис. 1,6 , с той разницей, что в нашем прогнозе простирание $R$-сколов в осевой прифундаментной зоне отклоняется от оси сдвига на угол $\varphi_{f}=10-15^{\circ}$. Объяснение этого отклонения видится в существенной латеральной неоднородности осевой части зоны сдвигания, которая в наших расчетах и прогнозах по ним не учитывалась.

Полученные результаты по прогнозу морфологии разрывов в глубине зон сдвигания (см. рис. 10) хорошо соответствуют природным разрывным структурам, наблюдаемым по данным 3D-сейсмики [Гогоненков и дp., 2007]. Это соответствие проявляется: в кулисообразной повторяемости $R$-сколов, в крутом наклоне этих сколов $\left(30-35^{\circ}\right)$ от вертикали навстречу движению блоков фундамента, в увеличивающейся амплитуде сбросовой компоненты смещений в средней части разреза и в отсутствии этих смещений вблизи поверхности, в развороте кулис сколов по мере приближения к подошве вплоть до субпараллельной оси сдвигания. Показано, что определяющая роль в формировании поверхностей $R$-сколов пропеллерообразного вида в глубине зоны сдвигания связана с неоднородностью сдвига, а появление сбросовой компоненты смещений определяется существованием девиатора гравитационных напряжений. Отметим, что в работах [Koronovsky et al., 2009; Goncharov, 2010] при моделировании зон горизонтального сдвигания был предложен ряд гипотез о механизме формирования структур разрушения. На их основе кроме стандартно создаваемого сдвига блоков основания модели (см. рис. 2, в) был предложен способ нагружения, названный М.А. Гончаровым «горизонтальным сдвигом вдоль вертикальной плоскости». Этому нагружению отвечает приложение нагрузки к поверхности модели, что противоречит физи- ческому состоянию исследуемого геологического объекта. Необходимость введения подобного механизма нагружения была обусловлена именно тем фактом, что при моделировании не соблюдались условия подобия по ГНС (авторы этих экспериментов исходили из автоматического выполнения условий подобия [Белоусов, Гончаров, 1991; Методы моделирования..., 1988]) и, как следствие, в модели не возникали разрывные структуры со значимой сбросовой компонентой (см. рис. 10).

\section{5. О МОРФОЛОГИИ ТРЕЩИН В ГЛУБИНЕ ЗОНЫ ГОРИЗОНТАЛЬНОГО СДВИГАНИЯ}

С учетом всего комплекса трещин, формирование которых возможно на разных стадиях нагружения зоны горизонтального сдвигания, можно говорить, что с увеличением глубины системы вертикальных сдвигов по простиранию будут осложнены крутонаклоненными (30-35 от вертикали) сбросами и сбросо-сдвигами, формирующимися соответственно в ходе последней стадии нагружения (часть разрывов активизируется в ходе второй стадии). Здесь возможно появление сдвиго-сбросов и сдвиго-взбросов как следствие активизации на втором и третьем этапах особо ориентированных сбросов, возникших в начальном ГНС. Наиболее проявленные сбросо-сдвиги с простиранием 30-45 приурочены к зоне локализации горизонтального сдвига (третья стадия нагружения).

На еще больших глубинах вертикальные сдвиги будут встречаться только в осевой части локализирующейся области горизонтального сдвигания. На этих глубинах вдоль крутонаклоненных сколов будет наблюдаться практически только сбросовая компонента. Существует несколько локальных максимумов плотности полюсов сбросов, наибольшие из которых относятся к последней стадии нагружения (сопряженные сколы в слое над разными блоками фундамента). Здесь также могут наблюдаться разрывы, образовавшиеся в начальном состоянии, активизировавшиеся на заключительной стадии как сдвиго-сбросы и сдвиго-взбросы. Близкие выводы об изменении морфологических признаков по падению разрывов на больших глубинах можно найти в работе С.И. Шермана [1977].

При приближении к подошве слоя $(Y<0.2 H)$ вдоль крутонаклоненных сбросов вновь появляется сдвиговая компонента (третья стадия), которая непосредственно у фундамента и вблизи осевой части зоны сдвигания становится превалирующей. Здесь также будут наблюдаться и чистые разноориентированные сбросы, формировавшиеся на первой стадии нагружения.

Анализ парагенезов трещин, возникающих при механизме горизонтального сдвига, показал их широкое многообразие. При анализе только ориентации трещин локальные максимумы их полюсов создают сложную картину, на основе которой вполне допустимо выделение ложных стадий нагружения. Возможно, привлече- 
ние и данных о бороздах скольжения позволит произвести корректную реконструкцию режимов нагружения. Однако, скорее всего, для этого требуется произвести вычленение главных парагенезов, так как второстепенные способны привести к фиктивным решениям. В любом случае полученный синтетический парагенез трещин требует внимательного анализа и обсуждения.

\section{4. ЗАКЛЮЧЕНИЕ}

Наши исследования, прежде всего, показали необходимость учета при тектонофизическом моделировании девиаторной составляющей гравитационных напряжений. Длительное существование этой компоненты тензора ГНС обусловлено особенностями реологии горных пород, которая в условиях верхней коры и осадочного чехла отождествляется с катакластической пластичностью и ползучестью, также зависящей от всестороннего давления. Наличие в горных породах девиатора гравитационных напряжений требует выполнения условий подобия по силе тяжести при моделировании структур разрушения и/или геологических объектов с выраженным рельефом. Другим следствием этого является необходимость использовать при моделировании материалы с коэффициентом Пуассона, близким к его реальному значению для горных пород. Это создает практически непреодолимые трудности на пути физического моделирования структур разрушения и выдвигает математическое - численное - моделирование на ведущие позиции в тектонофизическом эксперименте. Использование физического моделирования для изучения структур разрушения требует создания новых материалов, обладающих наряду с низкомодульностью и малой прочностью и значениями упругого коэффициента Пуассона в диапазоне от 0.20 до 0.35. Об этом в свое время писал Г.И. Гуревич [1959] в дискуссии с М.В. Гзовским [1960].

Возвращаясь к указанной ранее гипотезе автоматического выполнения условий подобия [Гуревич, 1959; Goncharov, 2010], отметим, что рассмотренный в настоящей статье механизм деформирования геологического объекта - горизонтальное сдвигание - не дает такой возможности, если результатом моделирования является объяснение морфологии хрупких разрывов. Идея автоматического выполнения условий подобия годится лишь для моделей без выраженного рельефа при изучении очень длительных процессов без анализа разрывных структур, тогда, когда можно предполагать влияние на процесс деформирования одного источника нагружения. Оказалось, что те частности, от которых нам предлагал отказаться выдающийся тектонист В.В. Белоусов («... в огромном большинстве случаев при тектоническом моделировании подобие просто не нужно... Мы должны лишь при этом отказаться от выяснения частностей процесса..» [Методы моделирования..., 1988, стр. 21-22], критически важны при объ- яснении тонкой структуры широкого ряда деформационных процессов и явлений. Как показано в работах [Ребецкий, 2008a, 2008б, 2009; Rebetsky, 2008], ряд важных явлений, связанных с ролью ГНС в процессах формирования и современного состояния континентальной коры, на которые обращал внимание В.В. Белоусов, были нами утеряны или неправильно объяснялись из-за использования представлений об отсутствии девиаторной компоненты этого состояния. Здесь также хотелось бы заметить, что тезис об автоматическом выполнении условий подобия [Koronovsky et al., 2009; Goncharov, 2010] приводит к снятию с повестки дня необходимости исследования механических свойств модельных материалов. В недавно опубликованной работе А.Н. Бокуна [Bokun, 2009], посвященной моделированию зоны горизонтального сдвигания, показано, как разные реологические свойства модельного материала приводят к формированию различающихся по морфологии деформационных и разрывных структур.

Прогноз морфологии структур разрушения, сделанный на основе математического моделирования, показал важность моделирования геологического объекта с учетом эволюции его нагружения. Необходим учет не только начальной стадии - ГНС, но и стадии однородного горизонтального сдвигания, предваряющей локализованные смещения вдоль разлома фундамента. В рамках исследования эволюции напряженного состояния в глубине зоны горизонтального сдвигания установлен сложный, меняющийся с глубиной характер морфологии трещин. Наличие такого сложного парагенеза трещин может приводить к серьезным трудностям при применении методов тектонофизической реконструкции природных напряжений по данным только о трещиноватости. Здесь более перспективными выглядят методы реконструкций, опирающиеся на анализ борозд скольжения [Гущенко, 1979; Сим, 1996]. Следует заметить, что еще в работах [Price, 1959; Kakimi, 1971; Шерман, 1977 в упрощенной с позиции механики форме исследовалось изменение морфологии разрывов в глубине зоны однородного горизонтального сжатия, связанное именно с влиянием девиаторной компоненты начального гравитационного напряженного состояния. В настоящей работе эти идеи были реализованы для исследования в рамках теории пластичности существенно более сложной структурной зоны - области горизонтального сдвигания осадочного чехла.

Автор приносит благодарность Г.Н. Гогоненкову и А.И. Тимурзиеву за плодотворные научные обсуждения и предоставленные данные по 3D-сейсмике, которые сыграли главную роль в переосмыслении рассматриваемой проблемы. Работа финансировалась в рамках грантов РФФИ 09-05-00687, 09-05-01022, 07-05-00106, проекта № 5 ОН3 РАН (2006-2008 гг.), а также в рамках проекта Центральной геофизической экспедиции (договор с ОАО «Сибнефть-Ноябрьскнефтегаз»). 


\section{5. ЛИТЕРАТУРА}

Айтматов И.Т. Геомеханика рудных месторождений Средней Азии. Фрунзе: Илим, 1987. 246 с.

Белоусов В.В., Гончаров М.A. Автоматическое выполнение условий подобия в простейших случаях тектонического моделирования // Экспериментальная тектоника и полевая тектонофизика. Киев: Наукова думка, 1991. С. 16-20.

Бокун А.Н. Некоторые закономерности образования разрывных зон в осадочном чехле при погружении блоков фундамента (по результатам физического моделирования) // Эксперим. тектон. и полевая тектонофизика. Киев: Наукова думка. 1991. С. 112 120.

Борняков C.A Тектонофизический анализ процесса формирования трансформной зоны в упруговязкой модели // Проблемы разломной тектоники. Новосибирск, 1981. С. 26-44.

Борняков C.A. Динамика развития деструктивных зон межплитных границ (результаты моделирования) // Геология и геофизика. 1988. № 6. C. 3-10.

Вернон P.X. Метаморфические процессы. М.: Недра, 1980. 227 с.

Гзовский M.B. Моделирование тектонических процессов // Проблемы тектонофизики. М.: Госгеолтехиздат, 1960. С. 315-344.

Гзовский М.В. Основы тектонофизики. М.: Наука, 1975. 536 с.

Гинтов O.Б. Полевая тектонофизика и ее применение при изучении деформаций земной коры Украины. Киев: Феникс, 2005. 572 с.

Гогоненков Г.Н., Кашик А.С., Тимурзиев А.И. Горизонтальные сдвиги фундамента Западной Сибири // Геология нефти и газа. 2007. № 3. С. 3-11.

Гудман Р. Механика скальных пород. М.: Стройиздат, 1987. 232 с.

Гуревич Г.И. Об исходных предпосылках моделирования в тектонофизике // Труды ИФЗ АН СССР. 1959. № 2 (169). С. 75-144.

Гутерман В.Г. Механизмы тектогенеза. Киев: Наукова думка. 1987. $171 \mathrm{c.}$

Гущенко О.И. Метод кинематического анализа структур разрушения при реконструкции полей тектонических напряжений // Поля напряжений в литосфере. М.: Наука, 1979. С. 7-25.

Давиденков Н.Н. Об остаточных напряжениях // Рентография в применении к исследованиям материалов. М.-Л.: ОНТИ, 1936.

Джагер Ч. Механика горных пород и инженерные сооружения. М.: Мир, 1975. 255 с.

Динник A.H. О давлении горных пород и расчете крепи круглой // Инженерный работник. 1926. № 3. С. 1-12.

Либерман Ю.M. Естественное напряженное состояние массива горных пород // Труды ВНИИСТ. Вып. 12. М., 1962.

Марков Г.А. Тектонические напряжения и горное давления в рудниках Хибинского массива. Л.: Наука. Ленинград. отд-е, 1977. 211 c.

Методы моделирования в структурной геологии / В.В. Белоусов, А.В. Вихерт, М.А. Гончаров и др. М.: Недра, 1988. 222 с.

Михайлова A.B. Методические вопросы создания и исследования тектонических моделей с применением пластичных эквивалентных материалов // Экспериментальная тектоника: методы, результаты, перспективы. М.: Наука, 1989. С. 209-227.

Михайлова A.B. Исследование механизмов формирования тектонических структур в слое над активными разломами фундамента в свете учения М.Г. Гзовского // Тектонофизика сегодня. М.: ОИФЗ РАН, 2002. С. 212-224.

Михайлова A.B., Осокина Д.Н. Изучение соотношений между характеристиками вертикальных перемещений поверхности и величиной деформаций на глубине (на моделях) // Современные движения земной коры. № 5. Тарту, 1973. С. 589-594.

Надаи А. Пластичность и разрушение твердых тел. М.: Иностранная литература, 1954. 647 с.

Николаевский В.Н. Граница Мохоровичича как предельная глубина хрупко-дилатансионного состояния горных пород // Доклады АН СССР. 1979. Т. 249. № 4. С. 817-820.

Николаевский В.Н. Геомеханика и флюидодинамика. М.: Недра, 1996. 446 с.

Осокина Д.Н. Пластичные оптически активные материалы для моделирования тектонических процессов // Проблемы тектонофизики. М.: Госгеолтехиздат, 1960.

Осокина Д.Н. Пластичные и упругие низкомодульные оптическиактивные материалы для исследования напряжений в земной коре методом моделирования. М.: АН СССР, 1963. 196 с.

Осокина Д.Н. О корреляции между затуханием упругих колебаний и сдвиговой вязкостью твердых тел и жидкостей // Тектонофизика и механические свойства горных пород. М.: Наука, 1971. С. 72-90.

Осокина Д.Н. Взаимосвязь смещений по разрывам с тектоническими полями напряжений и некоторые вопросы разрушения горного массива // Поля напряжений и деформаций в земной коре. М.: Наука, 1987. С. 120-135.

Парфенов В.Д., Жуковский С.Д. Моделирование хрупкого разрушения в условиях деформации сдвигания // Геотектоника. 1966. № 4. С. 112-117.

Рамберг $X$. Моделирование деформаций земной коры с применением центрифуги. М.: Мир, 1970. 224 с.

Ребецкий Ю.Л. Напряжённое состояние слоя при продольном горизонтальном сдвиге блоков его фундамента // Поля напряжений и деформаций в земной коре. М.: Наука, 1987. С. 41-57.

Ребецкий Ю.Л. Тектонические напряжения и прочность горных массивов. М.: Академкнига, 2007. 406 с.

Ребецкий Ю.Л. Механизм генерации остаточных напряжений и больших горизонтальных сжимающих напряжений в земной коре внутриплитовых орогенов // Проблемы тектонофизики. К 40-летию создания М.В. Гзовским лаборатории тектонофизики в ИФЗ РАН. М.: ИФЗ РАН, 2008а. С. 431-466.

Ребецкий Ю.Л. Механизм генерации тектонических напряжений в областях больших вертикальных движений землетрясений // Физическая мезомеханика. 2008б. Т. 11. № 1. С. 66-73.

Ребецкий Ю.Л. Гравитационное напряженное состояние и механизм генерации горизонтального сжатия // Тектонофизика и актуальные вопросы наук о Земле. К 40-летию создания М.В. Гзовским лаборатории тектонофизики в ИФЗ РАН: Материалы Всероссийской конференции (13-17 октября 2008 г.). М.: ИФЗ РАН, 2009. Т. 1. С. 75-92.

Ребецкий Ю.Л., Михайлова А.В., Сим Л.А. Тектонофизическое моделирование структур сдвигания // Проблемы тектонофизики. К 40-летию создания М.В. Гзовским лаборатории тектонофизики в ИФЗ РАН. М.: ИФЗ РАН, 2008. С. 103-140.

Ребецкий Ю.Л., Михайлова А.В., Сим Л.А. Морфология структур разрушения в глубине зон сдвигания по результатам математического моделирования // Тектонофизика и актуальные вопросы наук о Земле. К 40-летию создания М.В. Гзовским лаборатории тектонофизики в ИФЗ РАН: Материалы Всероссийской конференции (13-17 октября 2008 г.). М.: ИФЗ РАН, 2009. Т. 1. С. 182-207.

Семинский К.Ж. Внутренняя структура континентальных разломных зон. Тектонофизический аспект. Новосибирск. Изд-во СО РАН, филиал «Гео», 2003. 241 с.

Сим Л.А. Неотектонические напряжения Восточно-Европейской платформы и структур обрамления: Автореф. дис. ... докт. геол.-мин. наук. М.: МГУ, 1996. 41 с.

Стефанов Ю.П. Некоторые особенности численного моделирования поведения упруго-хрупкопластичных метериалов // Физическая мезомеханика. 2005. Т. 8. № 3. С. 129-142.

Стоянов С. Механизм формирования разрывных зон. М.: Недра, 1977. 144 c.

Терцаги K. Теория механики грунтов. М.: Госстройиздат, 1961. $507 \mathrm{c}$.

Шеменда А.И. Критерии подобия при механическом моделировании тектонических процессов // Геология и геофизика. 1983. № 10. С. 10-19.

Шерман С.И. Физические закономерности развития разломов земной коры. Новосибирск: Наука, 1977. 101 с.

Шерман С.И., Борняков С.А., Буддо В.Ю. Области динамического влияния разломов (результаты моделирования). Новосибирск: Наука. Сиб. отд-е, 1983. 110 с.

Шерман С.И., Семинский К.Ж., Борняков С.А. и др. Разломообра- 
зование в литосфере. Зоны сдвига. Новосибирск: Наука. Сиб. отд-е, 1991. 262 с.

Angelier J., Bergerat F., Stefansson R., Bellou M. Seismotectonics of a newly formed transform zone near a hot spot: Earthquake mechanisms and regional stress in the South Iceland seismic zone // Tectonophysics. 2008. V. 447. № 1-4. P. 95-116. doi:10.1016/j.tecto. 2006.07.016.

Bokun A.N. Horizontal shear zones: physical modeling of formation and structure // Izvestiya Physics of the Solid Earth. 2009. V. 45. № 11. P. 996-1005. doi:10.1134/S106935130911007X.

Byerlee J.D. Friction of rocks // Pure and applied geophysics. 1978. V. 116. P. 615-626. doi:10.1007/BF00876528.

Goncharov M.A. Applicability of similarity conditions to analogue modelling of tectonic structures // Geodynamics \& Tectonophysics. 2010. V. 1. № 2. P. 148-168.

Hancock P.L. Brittle mirotectonics: principles and practice // Journal of Structural Geology. 1985. V. 7. № 3-4. P. 437-457. doi:10.1016/ 0191-8141(85)90048-3.

Hardebeck J.L., Hauksson E. Crustal stress field in Southern California and its implications for fault mechanics // Journal of Geophysical Research. 2001. V. 106. № B10. P. 21859-21882. doi:10.1029/ 2001JB000292.

Harris L.B., Cobbold P.R. Development of conjugate shear bands during bulk simple shearing // Journal of Structural Geology. 1985. V. 7. № 1. P. 37-44. doi:10.1016/0191-8141(85)90113-0.

Hast $N$. The state of stresses in upper part of Erath's crust // Tectonophysics. 1969. V. 8. № 3. P. 169-211. doi:10.1016/0040-1951(69) 90097-3.
Heim A. Mechanismus der Gebirgsbidung. Bale, 1878.

Jager J.C. Elasticity fracture and flow. London: Methuen \&Co. Ltd., 1962. $208 \mathrm{p}$.

Kakimi T. Depth of fracturing in Earth's crust // Journal of the Geological Society of Japan. 1971. V. 77. № 5. P. 237-242.

Keller E.A., Bonkowski M.S., Korsch R.J., Shlemon R.J. Tectonic geomorphology of the San Andreas fault zone in the southern Indio Hills, Coachella Valley, California // Geological Society of America Bulletin. 1982. V. 93. № 1. P. 46-56. doi:10.1130/0016-7606(1982)93<46: TGOTSA $>2.0$. CO;2.

Koronovsky N.V., Gogonenkov G.N., Goncharov M.A., Timurziev A.I., Frolova N.S. Role of shear along horizontal plane in the formation of helicoidal structures // Geotectonics. 2009. V. 43. № 5. P. 379-391. doi:10.1134/S0016852109050033.

Price N.J. Mechanics of jointing in rock // Geological Magazine. 1959. V. 96. № 2. P. 149-167. doi:10.1017/S0016756800060040.

Rebetsky Yu.L. Stress state of the layer // Izvestia RAS Physics of the Earth. 1988. № 9. P. 698-703.

Rebetsky Yu.L. Possible mechanism of horizontal compression stress generation in the Earth's crust // Doklady Earth Sciences. 2008. V. 423A. № 9. P. 1448-1451. doi:10.1134/S1028334X08090274.

Reid H.F. The mechanism of the earthquake. The California earthquake of April 18, 1906. Rep. of the state investigation commiss. Washington, 1910. V. 2. Pt. 1.56 p.

Sylvester A.G. Strike-slip faults // Geological Society of America Bulletin. 1988. V. 100. № 11. P. 1666-1703. doi:10.1130/0016-7606 (1988)100<1666:SSF>2.3.CO;2.

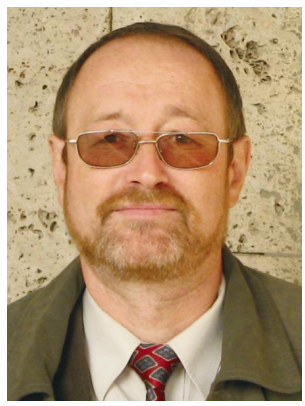

Ребецкий Юрий Леонидович, д.ф.-м.н., зав. лаб. тектонофизики Институт физики Земли им. О.Ю. Шмидта РАН 123995, ГСП-5, Москва Д-242, ул. Большая Грузинская, 10, Россия Тел.: 8-499-25493050; \ e-mail: reb@ifz.ru

Rebetsky, Yuri L., Doctor of Physics and Mathematics, Head of the Laboratory of Tectonophysics Schmidt Institute of Physics of the Earth RAS 123995, Moscow D-242, Bol'shaya Gruzinskaya street, 10, Russia

Tel.: 8-499-25493050; $\bowtie$ e-mail: reb@ifz.ru

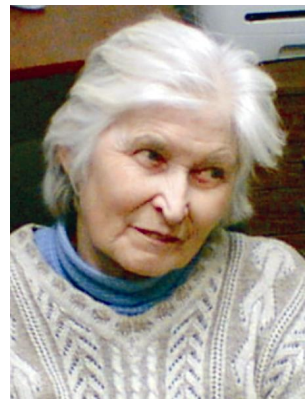

Михайлова Анастасия Всеволодовна, к.т.н., с.н.с.

Институт физики Земли им. О.Ю. Шмидта РАН

123995, ГСП-5, Москва Д-242, ул. Большая Грузинская, 10, Россия

Тел.: 8-499-25493050

Mikhailova, Anastasia V., Candidate of Technical Sciences, Senior Researcher Schmidt Institute of Physics of the Earth RAS 123995, Moscow D-242, Bol’shaya Gruzinskaya street, 10, Russia

Tel.: 8-499-25493050 